Article

\title{
In-Season Diagnosis of Rice Nitrogen Status Using Proximal Fluorescence Canopy Sensor at Different Growth Stages
}

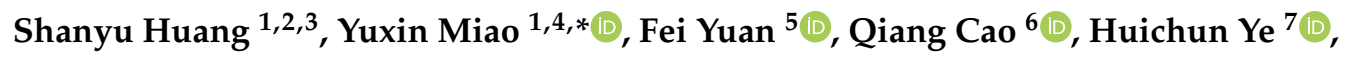 \\ Victoria I.S. Lenz-Wiedemann ${ }^{1,2}$ and Georg Bareth ${ }^{1,2}$ \\ 1 International Center for Agro-Informatics and Sustainable Development (ICASD), College of Resources and \\ Environmental Sciences, China Agricultural University, Beijing 100193, China \\ 2 Institute of Geography, University of Cologne, 50923 Köln, Germany \\ 3 Chinese Academy of Agricultural Engineering Planning \& Design, Beijing 100125, China \\ 4 Precision Agriculture Center, Department of Soil, Water and Climate, University of Minnesota, \\ St. Paul, MN 55108, USA \\ 5 Department of Geography, Minnesota State University, Mankato, MN 56001, USA \\ 6 National Engineering and Technology Center for Information Agriculture, Nanjing Agricultural University, \\ Nanjing 210095, China \\ 7 Key Laboratory of Digital Earth Science, Institute of Remote Sensing and Digital Earth, Chinese Academy of \\ Sciences, Beijing 100094, China \\ * Correspondence: ymiao@cau.edu.cn or ymiao@umn.edu; Tel.: +86-138-1104-8358 or +1-612-625-4731
}

Received: 7 July 2019; Accepted: 6 August 2019; Published: 8 August 2019

Abstract: Precision nitrogen $(\mathrm{N})$ management requires an accurate and timely in-season assessment of crop N status. The proximal fluorescence sensor Multiplex ${ }^{\circledR} 3$ is a promising tool for monitoring crop $\mathrm{N}$ status. It performs a non-destructive estimation of plant chlorophyll, flavonol, and anthocyanin contents, which are related to plant $\mathrm{N}$ status. The objective of this study was to evaluate the potential of proximal fluorescence sensing for $\mathrm{N}$ status estimation at different growth stages for rice in cold regions. In 2012 and 2013, paddy rice field experiments with five N supply rates and two varieties were conducted in northeast China. Field samples and fluorescence data were collected in the leaf scale (LS), on-the-go (OG), and above the canopy (AC) modes using Multiplex ${ }^{\circledR} 3$ at the panicle initiation (PI), stem elongation (SE), and heading (HE) stages. The relationships between the Multiplex indices or normalized N sufficient indices (NSI) and five N status indicators (above-ground biomass (AGB), leaf $\mathrm{N}$ concentration (LNC), plant $\mathrm{N}$ concentration (PNC), plant $\mathrm{N}$ uptake (PNU), and N nutrition index (NNI)) were evaluated. Results showed that Multiplex measurements taken using the OG mode were more sensitive to rice $\mathrm{N}$ status than those made in the other two modes in this study. Most of the measured fluorescence indices, especially the $\mathrm{N}$ balance index (NBI), simple fluorescence ratios (SFR), blue-green to far-red fluorescence ratio (BRR_FRF), and flavonol (FLAV) were highly sensitive to $\mathrm{N}$ status. Strong relationships between these fluorescence indices and $\mathrm{N}$ indicators, especially the LNC, PNC, and NNI were revealed, with coefficients of determination $\left(\mathrm{R}^{2}\right)$ ranging from 0.40 to 0.78 . The $\mathrm{N}$ diagnostic results indicated that the normalized $\mathrm{N}$ sufficiency index based on NBI under red illumination (NBI_R $\mathrm{N}_{\mathrm{NSI}}$ ) and FLAV achieved the highest diagnostic accuracy rate $(90 \%)$ at the SE and HE stages, respectively, while NBI_R ${ }_{\text {NSI }}$ showed the highest diagnostic consistency across growth stages. The study concluded that the Multiplex sensor could be used to reliably estimate $\mathrm{N}$ nutritional status for rice in cold regions, especially for the estimation of LNC, PNC, and NNI. The normalized N sufficiency indices based on the Multiplex indices could further improve the accuracy of $\mathrm{N}$ nutrition diagnosis by reducing the influences of inter-annual variations and different varieties, as compared with the original Multiplex indices. 
Keywords: Multiplex ${ }^{\circledR} 3$ sensor; nitrogen balance index; nitrogen nutrition index; nitrogen status diagnosis; precision nitrogen management

\section{Introduction}

Nitrogen $(\mathrm{N})$ is an essential nutrient for plant growth and development. However, excessive $\mathrm{N}$ fertilizer applications have led to severe environmental impacts in China [1,2]. Therefore, there has been a growing interest in developing precision $\mathrm{N}$ management strategies in agricultural research for many years. This requires the development of efficient and timely crop $\mathrm{N}$ status diagnosis strategies and technologies [3].

Plant or leaf $\mathrm{N}$ concentration is an indication of $\mathrm{N}$ nutritional status. The traditional $\mathrm{N}$ testing method in the laboratory is time-consuming and impractical for characterizing spatial and temporal variability in crop $\mathrm{N}$ status in precision $\mathrm{N}$ management. Alternatively, it is known that there is a strong relationship between plant chlorophyll content and $\mathrm{N}$ content, although other stress factors, such as water deficit, cold, heat, excess light, leaf or root pathogens, etc., can also influence chlorophyll content directly or indirectly [4,5]. Therefore, various instruments based on measuring chlorophyll have been developed to provide indirect, nondestructive, and real-time estimations of leaf $\mathrm{N}$ content $[3,6]$. For example, the Soil Plant Analysis Development chlorophyll meter (SPAD) developed by Minolta Camera Co. (Osaka, Japan) is a widely used portable instrument for measuring chlorophyll in leaves. The SPAD meter measures the difference in absorption between the red $(660 \mathrm{~nm})$ and near-infrared $(940 \mathrm{~nm})$ wavelengths $[7,8]$. Leaf chlorophyll absorbs red light but not infrared, therefore, the SPAD readings indicate plant chlorophyll concentration and $\mathrm{N}$ content [9-11]. However, the reliability of SPAD results is affected by factors such as growth stage, irradiance, water status, and leaf thickness [3,5,9].

Optical non-destructive remote sensing methods based on canopy reflectance measurements have also been widely used [12,13]. The high measuring efficiency of reflectance spectroscopy sensors and the strong correlation between their measurements and crop physiological and biochemical parameters offer a high potential for N management [14,15]. Proximal active sensors, such as GreenSeeker (NTech Industries, Inc., Ukiah, CA) and Crop Circle (Holland Scientific, NE, USA), have been used to diagnose $\mathrm{N}$ nutritional status in real-time and to guide in-season precision management for rice $\mathrm{N}$ fertilization [16,17]. However, the results based on the canopy reflectance are affected by various factors, such as soil characteristics, crop growth stages, and saturation under high biomass conditions [16,18]. In addition, it is more difficult to estimate chlorophyll or $\mathrm{N}$ status using optical remote sensing methods as the contribution of leaf area index and biomass to canopy reflectance is much greater than that of chlorophyll or $\mathrm{N}$ concentration $[19,20]$.

Unlike reflectance indices, the fluorescence spectra are less affected by biomass or leaf area index $[15,21]$. At different $\mathrm{N}$ nutritional levels, the fluorescence intensities of leaves are significantly different near the $440 \mathrm{~nm}$ (Blue, B), $525 \mathrm{~nm}$ (Green, G), 685-690 nm (Red, R), and 735-740 nm (Near-infrared, NIR) wavelengths [22,23]. Studies have shown that the fluorescence ratio of NIR and $\mathrm{R}$ bands is highly correlated with chlorophyll concentration [24,25] and leaf $\mathrm{N}$ concentration [26]. Because the fluorescence ratio is only related to chlorophyll concentration or photosynthetic activities, soil background does not affect the vegetation spectra at the early growth stages. Longchamps and Khosla [27] observed that $\mathrm{N}$ supply levels in corn could be differentiated as early as the V5 phenological stage using a proximal fluorescence sensor. In contrast, the test results only became reliable starting from the V8 growth stage based on reflective sensors [28,29]. Therefore, chlorophyll fluorescence sensing is a powerful solution to the shortcomings of proximal reflectance sensors in crop $\mathrm{N}$ status monitoring.

In addition to chlorophyll content, polyphenols (mainly flavonols) can also be used to estimate plant $\mathrm{N}$ status. When $\mathrm{N}$ is deficient, polyphenols increase significantly due to carbon and $\mathrm{N}$ balance regulation mechanisms [30], although an increase in polyphenol concentration may also be related to 
their photoprotective roles [31]. These compounds are mainly concentrated in epidermal cells and have typical absorption peaks in the ultraviolet region [31-33]. Thus, $\mathrm{N}$ status diagnosis is improved by combining the polyphenol and chlorophyll fluorescence [34,35]. Lejealle et al. [36] demonstrated that the $\mathrm{N}$ balance index (NBI), the ratio of chlorophyll to flavonol, had a better and more stable correlation with leaf $\mathrm{N}$ concentration. Leaf fluorescence sensor Dualex (FORCE-A, Orsay, Paris, France) and canopy fluorescence sensor Multiplex (FORCE-A, Orsay, Paris, France) can be used to estimate plant polyphenol contents as well as chlorophyll content. Thus, in addition to $\mathrm{N}$, these fluorescence sensors can detect physiological and biochemical plant parameters such as anthocyanins [37], or plant diseases [38]. Furthermore, Multiplex is a canopy sensor that is more efficient than a leaf sensor such as Dualex. It allows rapid large-area measurements with simultaneous GPS data recording for field map generation $[39,40]$. However, studies based on Multiplex are still limited, especially for rice $\mathrm{N}$ status diagnosis and precision $\mathrm{N}$ management. Zhang et al. [41] identified FERARI (fluorescence excitation ratio anthocyanin relative index), SFR_G (simple fluorescence ratio under green excitation), SPAD/DUAD (Dualex reading), and SPAD reading as valuable indicators for monitoring corn $\mathrm{N}$ status at early stages. In addition, they found leaf-scale (LS) Multiplex measurements were better related to $\mathrm{N}$ treatments than the Multiplex readings made from a small distance above the canopy (AC). Li et al. [42] reported that both leaf-based SPAD and canopy Multiplex indices could be used to predict rice leaf $\mathrm{N}$ contents. The on-the-go (OG) measurement mode means placing the sensor probe in the canopy close to the blade and continuously collecting data during the move. This mode is most efficient in data collection. In a recent study, Diago et al. [39] confirmed the capability of the Multiplex sensor using the OG mode to estimate key nutritional parameters in grapevine leaves in motion by calibrating Multiplex against the leaf-clip Dualex sensor. However, further systematic and comprehensive study is necessary to investigate the application potential of canopy fluorescence sensing for rice $\mathrm{N}$ status diagnosis in motion.

Hence, the main objectives of this study were to: (1) Determine the feasibility of using canopy multispectral fluorescence sensing system such as the Multiplex sensor to estimate $\mathrm{N}$ status in paddy rice by comparing the results of three measurement modes (LS, AC, and OG); and (2) establish and validate the estimation models for $\mathrm{N}$ indicators based on the optimal Multiplex indices. In addition, to reduce the influences of varieties, years, sites, and other factors, the normalized N sufficiency index (NSI) was calculated and included in the analysis of the fluorescence indices. Well-fertilized reference plots were used to normalize reflectance measurements as more stable rice $\mathrm{N}$ diagnostic results might be obtained when calculating the NSI [43].

\section{Materials and Methods}

\subsection{Experimental Design}

Two field trials were conducted at the Jiansanjiang Experiment Station of China Agricultural University $\left(47^{\circ} 15^{\prime} \mathrm{N}, 132^{\circ} 39^{\prime} \mathrm{E}\right)$, Sanjiang Plain, Heilongjiang Province, northeast China. The field experiments in 2012 and 2013 included five different $\mathrm{N}$ rates $\left(0,70,100,130,160 \mathrm{~kg} \mathrm{~N} \mathrm{ha}{ }^{-1}\right)$ and two Japonica rice varieties, Kongyu 131 (KY 131) and Longjing 21 (LJ 21). These two represent the main varieties in this region: KY131 has 11 leaves, four elongation nodes and about 127 maturity days, while LJ 21 has 12 leaves and needs 133 maturity days. Planting density was approximately 30 hills m$^{-2}$ for KY 131 and 28 hills $\mathrm{m}^{-2}$ for LJ 21, with an identical row spacing of $0.3 \mathrm{~m}$. The plot size was $4.5 \mathrm{~m} \times 9 \mathrm{~m}$. The $\mathrm{N}$ fertilizer applications were split into $40 \%, 30 \%, 30 \%$, and applied before the transplanting, at the active tillering stage, and at the stem elongation (SE) stage, respectively. Phosphate $\left(50 \mathrm{~kg} \mathrm{P}_{2} \mathrm{O}_{5} \mathrm{ha}^{-1}\right)$ fertilizers were applied before transplanting, and potash $\left(100 \mathrm{~kg} \mathrm{~K}_{2} \mathrm{O} \mathrm{ha}{ }^{-1}\right)$ fertilizers were applied as two splits, $50 \%$ as basal fertilizer and $50 \%$ as panicle fertilizer at the SE stage. The two experiments were carried out in a randomized complete block design with three replicates. Table 1 lists the details of the two experiments. 
Table 1. Details of nitrogen (N) rate experiments with two rice cultivars conducted during 2012-2013.

\begin{tabular}{ccccc}
\hline Experiment & Year & Cultivar & Transplanting Date & Sampling Date and Stage \\
\hline 1 & 2012 & KY 131 & 18 May & 21 June (PI), 29 June (SE), 23 July (HE) \\
1 & 2012 & LJ 21 & 18 May & 25 June (PI), 2 July (SE), 23 July (HE) \\
2 & 2013 & KY 131 & 17 May & 23 June (PI), 2 July (SE), 22 July (HE) \\
2 & 2013 & LJ 21 & 17 May & 28 June (PI), 6 July (SE), 27 July (HE) \\
\hline
\end{tabular}

PI: Panicle Initiation; SE: Stem Elongation; HE: Heading.

\subsection{Fluorescence Measurements}

The portable fluorescence sensor Multiplex ${ }^{\circledR} 3$ was used in this study. It is an active sensor involving four emission light sources (UV_A, green, red or blue) to excite the fluorescence in plant tissues. Generally, the UV_A (375 nm), green $(530 \mathrm{~nm})$, and red $(630 \mathrm{~nm})$ emission light sources were used for plant monitoring while the blue $(470 \mathrm{~nm})$ emission light source was used for calibration. The sensor has three filtered detectors for fluorescence recording including blue-green fluorescence (447 $\mathrm{nm})(\mathrm{BGF})$, red fluorescence $(665 \mathrm{~nm})(\mathrm{RF})$ and far-red fluorescence $(735 \mathrm{~nm})$ (FRF). The fluorescence measurements were not influenced by ambient light conditions [41].

All the variables provided by the Multiplex sensor and their explanations are listed in Table 2. There are nine measured single fluorescence variables under three excitations and ten calculated indices. The Simple Fluorescence Ratio (SFR) index is the ratio of the FRF and RF emission under red (SFR_R) or green (SFR_G) illumination. SFR is related to leaf chlorophyll content. Due to the chlorophyll absorption waveband overlapping with its fluorescence emission red band, the chlorophyll re-absorption occurs at the shorter red wavelength rather than at the far-red wavelength. Therefore, using the FRF as a reference, the absorption of the RF reflects the content of chlorophyll [24,44]. Accordingly, SFR increases as chlorophyll content increases. The Flavonols (FLAV) index compares the fluorescence emission density of the far-red fluorescence under ultraviolet (FRF_UV) and red excitation (FRF_R). It is related to the flavonoid concentration of the epidermal layer $[45,46]$. The $\mathrm{N}$ Balance Index (NBI) is defined as the ratio of SFR and FLAV [47]. Therefore, NBI is proportional to both chlorophyll and flavonoid concentrations. Blue-green to far-red fluorescence ratio (BRR_FRF) index is the ratio of BGF and FRF under UV excitation. The ratio of fluorescence emission at $440 \mathrm{~nm}$ and $740 \mathrm{~nm}\left(\mathrm{~F}_{440} / \mathrm{F}_{740}\right)$ wavelength has been shown to be sensitive to environmental changes and growth conditions, and can detect plant stress before visible symptoms occur $[18,48]$. The Anthocyanins (ANTH) index and FERARI are both proven to be correlated with skin anthocyanin content [49].

Measurements were taken in motion with the sensor bottom along and just touching the crop leaves on two representative rows in the center of each plot. The data collected from the two rows were averaged to represent the plot [50]. This approach was named "measuring in motion" or "on-the-go" (OG) mode. Notably, in the OG mode, the Multiplex sensor was placed right above the crop leaves manually while walking forward as it is impractical to use a motorized vehicle or to mount the sensor on a vehicle in paddy fields. For comparison purposes, data were also measured in the LS and AC modes. The leaf-borne measurements in the LS mode were collected in the laboratory by taking ten leaves in the second position from the top. In the AC mode, the measurements were collected in the field by randomly selecting ten representative hills and placing the Multiplex sensor at a distance of approximately $10 \mathrm{~cm}$ above each selected hill. The average reading was then used to represent the plot.

\subsection{Plant Sampling and Measurements}

At the PI, SE, and HE stages, for each plot three to six plant samples were collected in each plot from the same rows where fluorescence sensor measurements were acquired. Various $\mathrm{N}$ status indicators, including above-ground biomass (AGB), plant $\mathrm{N}$ concentration (PNC), leaf $\mathrm{N}$ concentration (LNC), plant $\mathrm{N}$ uptake (PNU), and $\mathrm{N}$ nutrition index (NNI), were determined. The detailed sampling dates and related information are listed in Table 1. Roots from all the plant samples were removed and 
the samples were cleaned with water and then separated into leaves, stems, and panicles (e.g., HE stage). All samples were dried at $105^{\circ} \mathrm{C}$ for half an hour to reduce plant metabolic activities. After being dried in an oven at $70-80^{\circ} \mathrm{C}$ to constant weight, the samples were weighed. $\mathrm{N}$ concentrations for leaves, stems, and panicles were determined using the standard Kjeldahl method. The PNC is the sum of the products of each organ's N concentration and its proportional weight. The PNU was determined by multiplying PNC by AGB. The NNI is defined as the ratio of the actual PNC $\left(N_{a}\right)$ and the critical $N$ concentration $\left(N_{c}\right)$, with $N_{c}$ being calculated following the equation developed for rice in this region [51].

Table 2. Description of the variables and indices recorded by the Multiplex sensor (modified from Table 1 by Zhang et al. [41]).

\begin{tabular}{ccc}
\hline Variables & Formula & Explanation \\
\hline BGF_UV & $/$ & Blue-green Fluorescence under UV excitation \\
RF_UV & $/$ & Red Fluorescence under UV excitation \\
FRF_UV & $/$ & Far-Red Fluorescence under UV excitation \\
BGF_G & $/$ & Reflected Blue-Green light under Green excitation \\
RF_G & $/$ & Red Fluorescence under Green excitation \\
FRF_G & $/$ & Far-Red Fluorescence under Green excitation \\
& & \\
RF_R & $/$ & Red Fluorescence under Red excitation \\
FRF_R & $/$ & Far-Red Fluorescence under Red excitation \\
SFR_G & FRF_G/RF_G & Simple Fluorescence Ratio under Green excitation \\
SFR_R & FRF_R/RF_R & Simple Fluorescence Ratio under Red excitation \\
BRR_FRF & BGF_UV/FRF_UV & Blue-green to Far-Red Fluorescence Ratio under UV excitation \\
FER_RUV & FRF_R/FRF_UV & Flavonols under Red and UV excitation \\
FLAV & Log (FRF_R/FRF_UV) & Flavonols under Red and UV excitation \\
FER_RG & FRF_R/FRF_G & Anthocyanins under Red and Green excitation \\
ANTH & Log (FRF_R/FRF_G) & Anthocyanins under Red and Green excitation \\
NBI_G & FRF_UV/RF_G & Nitrogen Balance Index under UV and Green excitation \\
NBI_R & FRF_UV/RF_R & Nitrogen Balance Index under UV and Red excitation \\
FERARI & Log (5000/FRF_R) & Fluorescence Excitation Ratio Anthocyanin Relative Index \\
\hline
\end{tabular}

\# the variable is not measured in the "on-the-go" mode.

\subsection{Statistical Analysis}

The Multiplex data of the three measurement modes at each sampling stage, year, and cultivar obtained under the varied $\mathrm{N}$ supply were subjected to analysis of variance (ANOVA) using SAS software (SAS Institute, Cary, NC, USA). Moreover, the means for each treatment were compared using the least significant difference (LSD) test at the 95\% level of significance. Relationships between the Multiplex indices and $\mathrm{N}$ status indicators were determined. All of the in-situ samples were divided into two groups by a stratified random sampling method, with approximately $2 / 3$ of the data used for model calibration and the remaining for model validation. Simple linear regression analyses were performed with SPSS 20.0 (SPSS Inc., Chicago, Illinois, USA). The coefficient of determination $\left(\mathrm{R}^{2}\right)$ was calculated for comparison. The relationships between Multiplex indices and N status indicators established at different growth stages were validated. The root mean square error (RMSE) and the relative error (RE), shown in Equations (1) and (2), between the predicted and observed values were used for evaluation.

$$
\begin{gathered}
\mathrm{RMSE}=\sqrt{\frac{1}{n} \sum_{i=1}^{n}\left(y_{i}-\hat{y}_{i}\right)^{2}} \\
\mathrm{RE}(\%)=\frac{R M S E}{\bar{y}} \times 100
\end{gathered}
$$

where $y_{i}, \hat{y}_{i}$, and $\bar{y}$ were the observed, predicted, and mean value, respectively. 
In order to evaluate normalized vegetation indices for improving the estimation of $\mathrm{N}$ nutrition indicators, the well-fertilized plots were used as $\mathrm{N}$ sufficient reference to calculate the NSI index. The NSI index equals to the ratio of Multiplex indices of the plots receiving normal $\mathrm{N}$ rates and the well-fertilized plots. In this study, the treatment with the largest shoot dry matter was defined as the well-fertilized plot, corresponding to the treatment of 130 or $160 \mathrm{~kg} \mathrm{~N} \mathrm{ha}^{-1}$.

Finally, the NNI diagnostic results of validation data using Multiplex indices were compared to the observed NNI by areal agreement and Kappa statistics [52]. Both used the same diagnostic criteria: $\mathrm{N}$ was deficient when NNI $<0.95, \mathrm{~N}$ was optimal when NNI is between $0.95-1.05$, and $\mathrm{N}$ was in surplus when NNI $>1.05$. The areal agreement (\%) and Kappa statistics were used to determine the accuracy of the diagnostic results. The areal agreement indicates the percentage of two groups sharing a common category or diagnostic class [53]. The Kappa statistic is a more robust measure of the agreement of two classifications by correcting the agreement that occurs by chance. When Kappa equals 1 , it indicates that the two categorization systems are identical. Kappa $\geq 0.60$ indicates a satisfactory agreement, while the Kappa $<0.4$ indicates weak agreement [54].

\section{Results}

\subsection{Comparison of the Three Measurement Modes}

The three aforementioned measurement modes were applied for each treatment plot. The results were compared to determine the best measurement mode. The abbreviation of the measurement mode is added to the variable as a prefix. For example, AC_SFR_G represents the Multiplex index SFR_G obtained from above the canopy.

Figure 1 shows box plots of Multiplex indices obtained from the three measuring modes at two phenological stages. Since FLAV and ANTH are the log transformation values of FER_RUV and FER_RG, only FLAV and ANTH were selected for the analysis to avoid duplication. During both the PI and SE growth stages, the mean values of the Multiplex indices (except for the BRR_FRF) obtained using the OG mode were significantly higher $(\mathrm{P} \leq 0.05)$ than the leaf-borne indices measured in the LS mode, whereas the latter were significantly higher than the measurements obtained in the AC mode. In addition, substantial large data ranges were shown in the NBI_G and NBI_R indices measured in motion and the leaf-borne BRR_FRF value.

The ANOVA results are listed in Table 3, indicating the sensitivities of the Multiplex indices to five $\mathrm{N}$ rates $\left(0,70,100,130\right.$, and $\left.160 \mathrm{~kg} \mathrm{~N} \mathrm{ha}^{-1}\right)$. $\mathrm{N}$ fertilization treatment effects were significant for most of the Multiplex variables measured in the OG mode whereas the opposite was true for the leaf-borne measurements. Comparatively, the $\mathrm{N}$ treatment effects were more significant for the readings obtained in the OG mode than those collected in the AC mode, while the measurements collected using the LS mode showed the minimum sensitivity to $\mathrm{N}$ rate changes. As an example, Figure 2 further demonstrates the comparison of the selected Multiplex indices at each $\mathrm{N}$ application rate for cultivar KY 131 in 2013. From Figure 2 we can also see that the indices measured using the OG mode could better distinguish the effects of $\mathrm{N}$ supply compared to the other two modes. Especially, the Multiplex indices measured in the OG mode performed consistently better than the others for differentiating high $\mathrm{N}$-application treatment $\left(\geq 100 \mathrm{~kg} \mathrm{ha}^{-1}\right)$ effects. Similar results were achieved for the variety LJ 21, or for the experiments conducted in 2012.

In conclusion, the ANOVA analysis results showed that most of the Multiplex variables obtained in the OG mode were more sensitive to $\mathrm{N}$ supply, followed by the AC modes, while measurements made in the LS mode were the least influenced by N supply (Table 3, Figure 2). Thus, only the results of the OG mode were used for further analysis and discussion. 

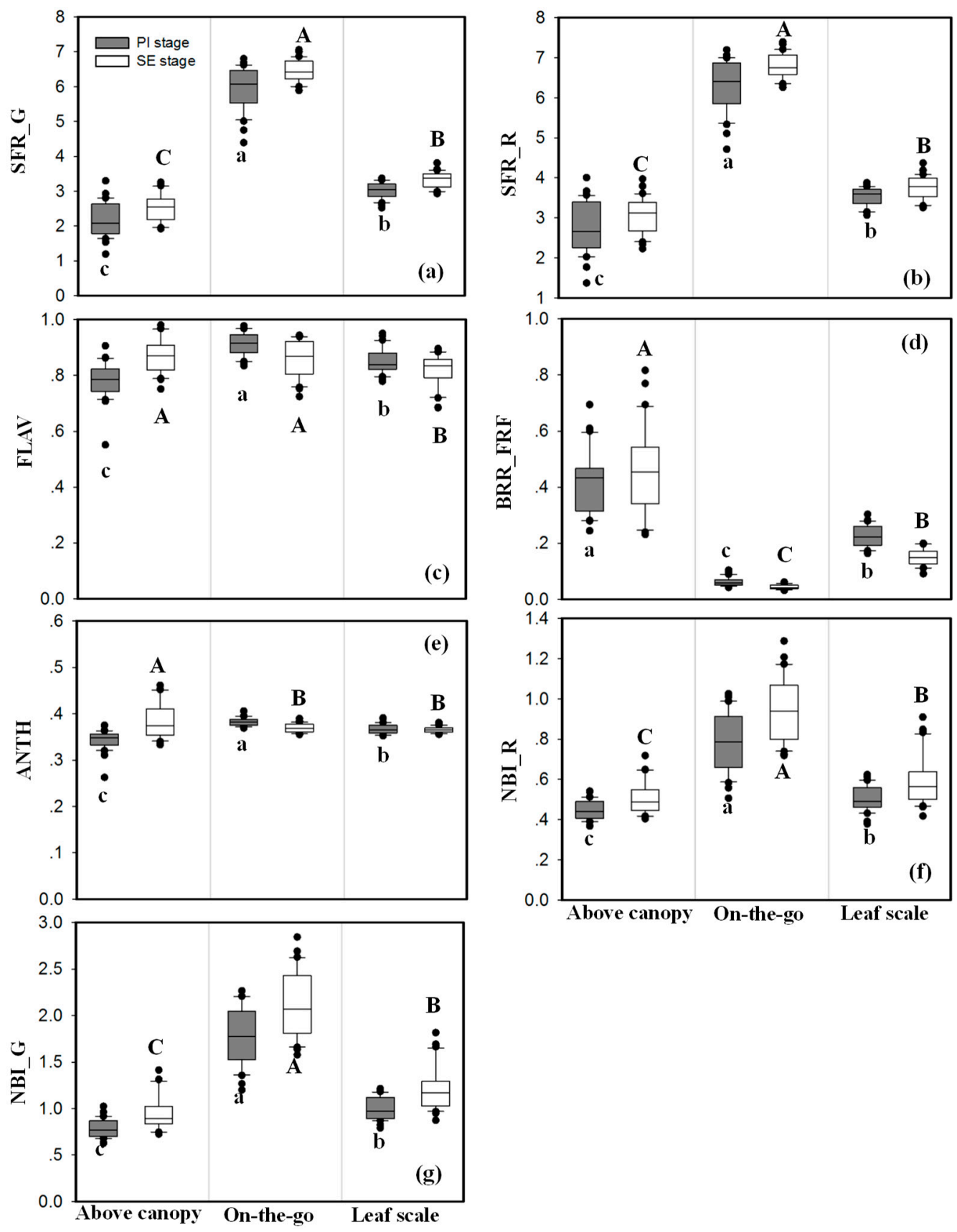

Figure 1. Box plots of selected Multiplex index values for the above canopy, on-the-go, and leaf scale measuring modes at the panicle initiation and stem elongation stages in 2013: Simple fluorescence ratio under green excitation (SFR_G) (a), simple fluorescence ratio under red excitation (SFR_R) (b), flavonol (FLAV) (c), blue-green to far-red fluorescence ratio (BRR_FRF) (d), anthocyanins (ANTH) (e), nitrogen balance index under UV and red excitation (NBI_R) (f), and nitrogen balance index under UV and green excitation (NBI_G) (g). Within the same growth stage, different lowercase (panicle initiation stage) or uppercase letters (stem elongation stage) above or below the boxes indicate that the Multiplex index values differed significantly according to the least significant difference test at $\mathrm{P} \leq 0.05$. 
Table 3. Significance test (ANOVA) of Multiplex variables measured in three modes across $5 \mathrm{~N}$ rates: Above canopy (AC), "on-the-go" (OG), and leaf scale (LS) at the panicle initiation (PI), stem elongation (SE), and heading (HE) growth stages for the rice varieties Kongyu 131 (KY 131) and Longjing 21 (LJ 21 ) in 2013.

\begin{tabular}{|c|c|c|c|c|c|c|c|c|c|c|c|c|c|c|c|c|c|}
\hline Variety & Stage & BGF_U V & RF_UV & FRF_UV & BGF_G & RF_G & FRF_G & RF_R & FRF_R & SFR_G & SFR_R & BRR_FRF & FLAV & ANTH & NBI_G & NBI_R & FERARI \\
\hline \multirow{11}{*}{ KY 131} & \multicolumn{17}{|c|}{ AC measurement mode } \\
\hline & PI & NS & * & * & NS & * & * & * & * & $* *$ & ** & NS & NS & NS & NS & NS & ** \\
\hline & SE & NS & NS & NS & NS & NS & NS & NS & NS & NS & * & NS & NS & NS & $*$ & NS & NS \\
\hline & \multicolumn{17}{|c|}{ OG measurement mode } \\
\hline & PI & $* * *$ & $* *$ & $* *$ & $* *$ & $* * *$ & $* * *$ & $* * *$ & $* * *$ & $* * *$ & $* * *$ & ** & * & * & ** & ** & \\
\hline & SE & $* *$ & $* * *$ & $* * *$ & NS & $* *$ & $* * *$ & $* *$ & $* *$ & $* *$ & $* *$ & $* *$ & $* *$ & $* *$ & $* *$ & $* *$ & \\
\hline & HE & NS & $* * *$ & $* * *$ & NS & $* *$ & $* *$ & * & $* *$ & $* *$ & $* *$ & $* *$ & $* *$ & $* *$ & $* * *$ & $* * *$ & \\
\hline & \multicolumn{17}{|c|}{ LS measurement mode } \\
\hline & PI & NS & NS & NS & NS & NS & NS & NS & * & * & * & NS & NS & NS & NS & NS & NS \\
\hline & SE & NS & NS & NS & NS & NS & $*$ & NS & * & $* * *$ & $* *$ & NS & NS & NS & $* *$ & $*$ & $*$ \\
\hline & HE & NS & NS & NS & $* *$ & NS & $*$ & NS & $*$ & $* *$ & * & $*$ & NS & NS & * & * & * \\
\hline \multirow{11}{*}{ LJ 21} & \multicolumn{17}{|c|}{ AC measurement mode } \\
\hline & PI & NS & * & * & NS & * & * & $*$ & * & ** & $* *$ & $* *$ & * & * & ** & * & $* *$ \\
\hline & SE & NS & * & * & NS & $*$ & $*$ & $*$ & $*$ & * & * & $* *$ & NS & NS & NS & NS & * \\
\hline & \multicolumn{17}{|c|}{ OG measurement mode } \\
\hline & PI & NS & * & * & NS & NS & * & NS & * & $* *$ & $* *$ & * & * & * & $* *$ & $* *$ & \\
\hline & SE & NS & $* *$ & $* *$ & NS & NS & $* *$ & NS & $* *$ & $* * *$ & $* * *$ & $*$ & $*$ & * & $* *$ & $* *$ & \\
\hline & HE & NS & $* * *$ & $* * *$ & NS & $* *$ & $* * *$ & NS & $* * *$ & $* * *$ & $* * *$ & $* * *$ & $* * *$ & NS & $* * *$ & $* * *$ & \\
\hline & \multicolumn{17}{|c|}{ LS measurement mode } \\
\hline & PI & NS & NS & NS & NS & NS & NS & NS & NS & $*$ & $* *$ & NS & NS & NS & * & NS & NS \\
\hline & SE & NS & ** & $* *$ & NS & NS & * & NS & NS & * & NS & ** & NS & NS & * & * & * \\
\hline & HE & NS & NS & NS & NS & NS & NS & NS & NS & NS & NS & NS & NS & NS & NS & NS & NS \\
\hline
\end{tabular}


1) Panicle initiation

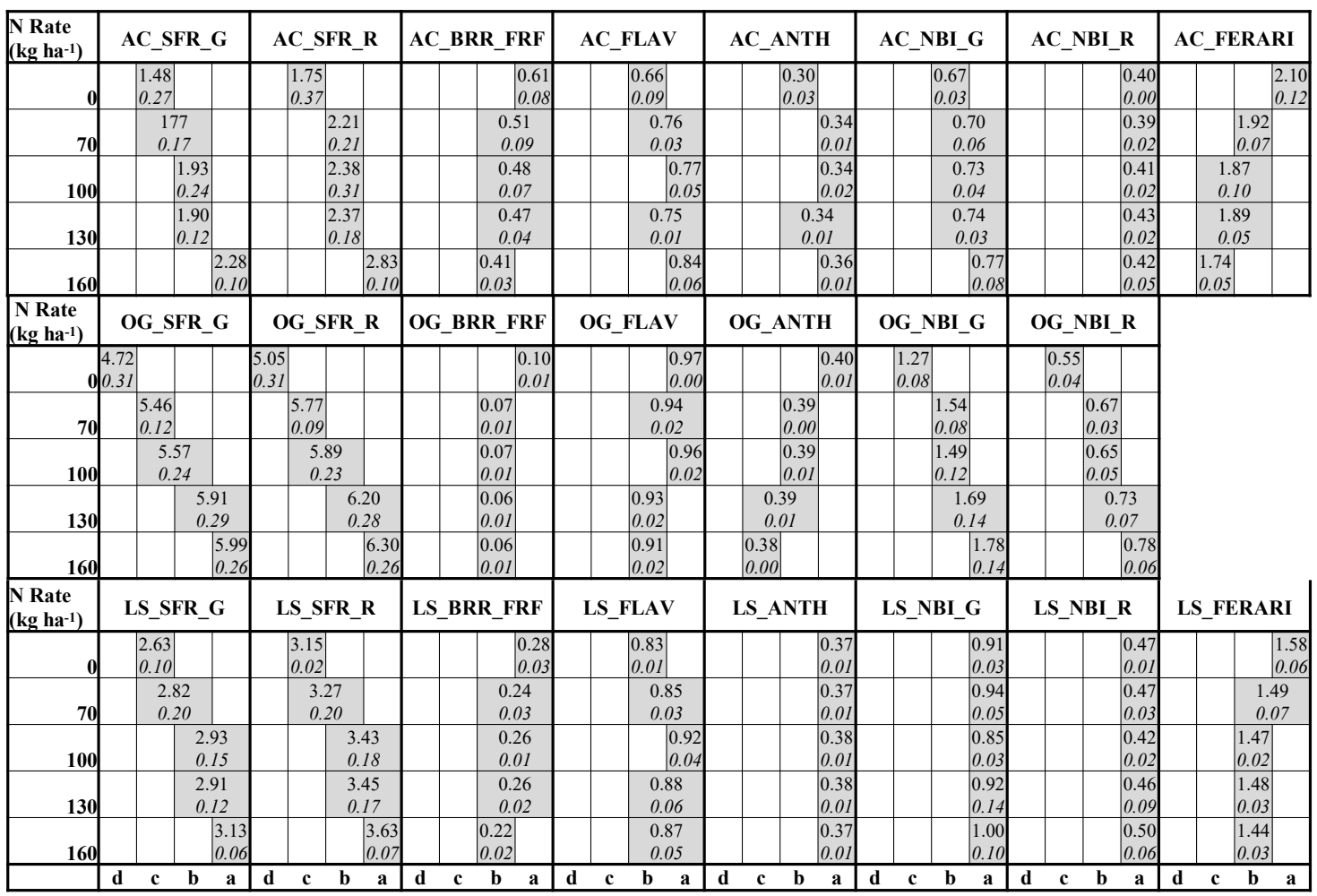

2) Stem elongation

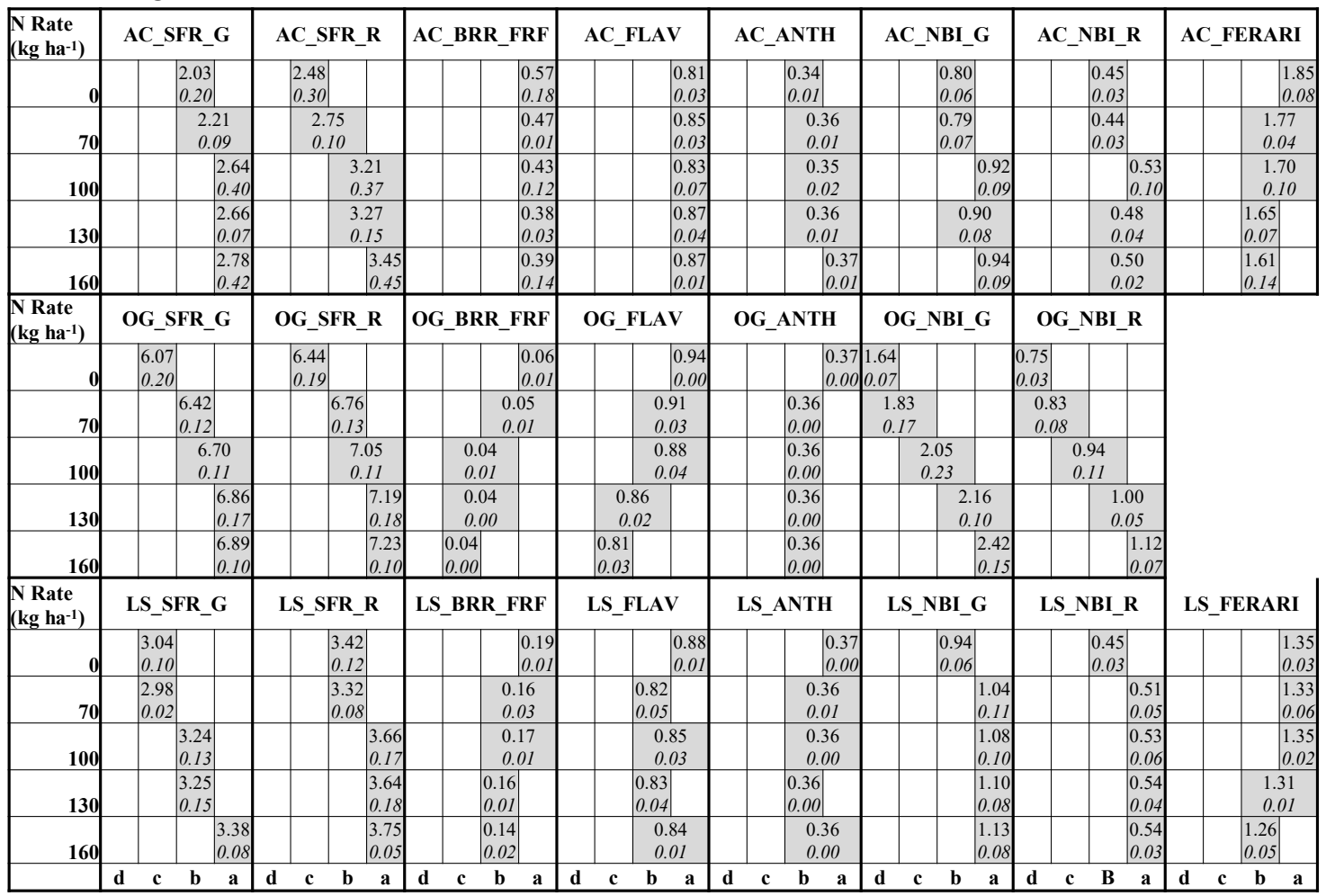

Figure 2. Cont. 
3) Heading

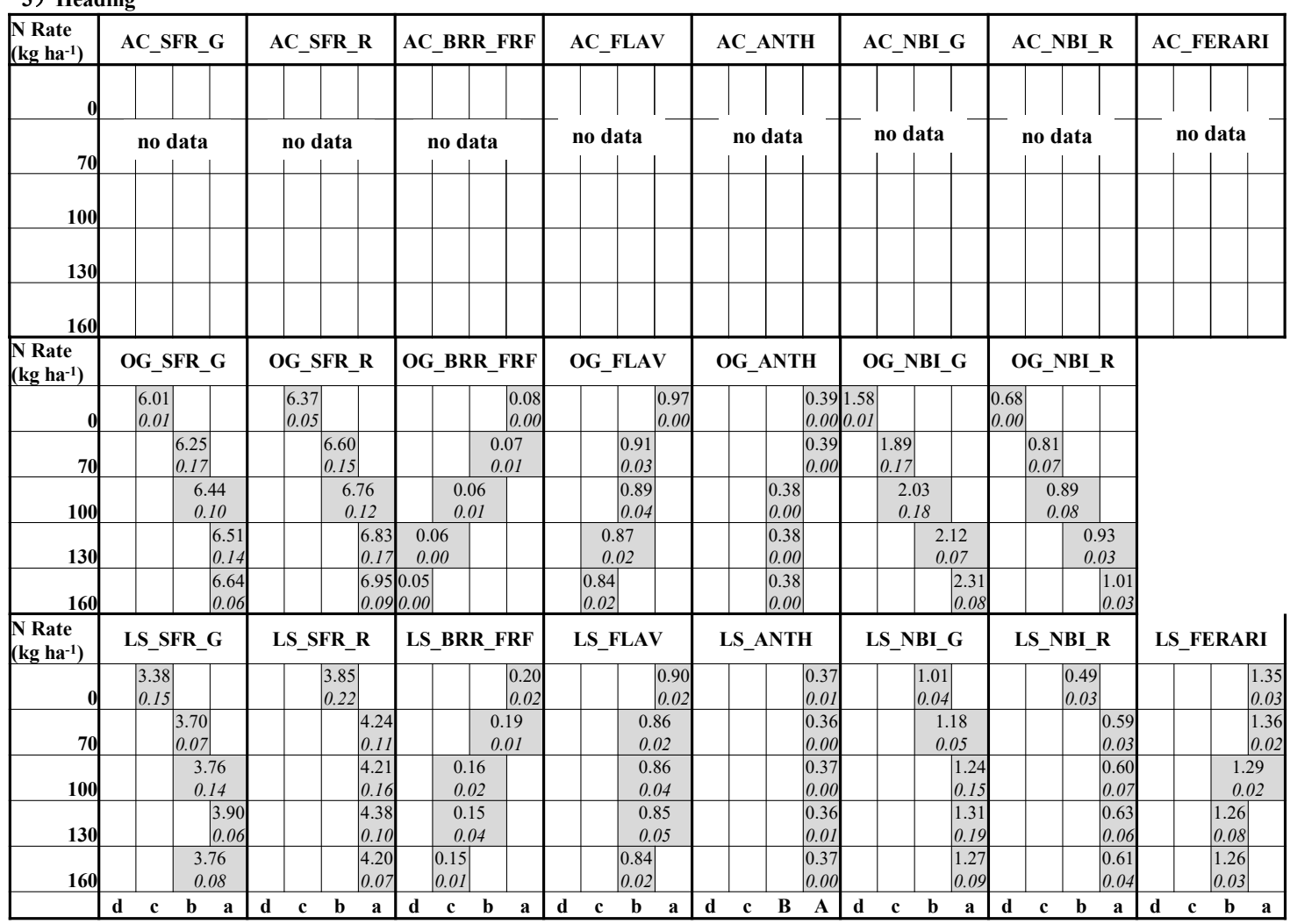

Figure 2. Mean value comparisons for each Multiplex index at the three growth stages and each $\mathrm{N}$ application rate $\left(\mathrm{kg} \mathrm{N} \mathrm{ha}^{-1}\right)$ for variety KY 131 in 2013. Means and standard errors are shown in each cell for $\mathrm{N}$ rate treatments with each measurement mode (Above Canopy, AC; On-the-go, OG; Leaf Scale, LS). Different lowercase letters at the bottom of the plot at each growth stage indicate significant differences according to the least significant difference test at $\mathrm{P} \leq 0.05$.

\subsection{Changes in Multiplex Indices ("On-The-Go" Mode) over Growth Stages under Different N Supplies}

The SFR_G, SFR_R, NBI_G, and NBI_R indices demonstrated an increasing trend as N rate increased, while a decreasing trend was shown for FLAV (Figure 2). Comparatively, the ANTH and BRR_FRF values were less sensitive to the changes in N rates. The values of these SFR_G, SFR_R, NBI_G, and NBI_R indices increased from the PI to SE stage but decreased slightly from the SE to HE stage, because the panicle formation decreased the chlorophyll/ $\mathrm{N}$ concentration in the upper layer at the HE stage. The opposite was true for the BRR_FRF, FLAV, and ANTH. NBI_G and NBI_R could differentiate different $\mathrm{N}$ application rates the best regardless of the growth stages, followed by SFR_G, SFR_R, BRR_FRF, and FLAV. The performance of ANTH was the worst (Figure 2).

\subsection{Correlations between Multiplex Indices ("On-The-Go" Mode) and N Status Indicators}

The linear regression results of the seven Multiplex indices and the five $\mathrm{N}$ status indicators at three growth stages across the two rice varieties are shown in Table 4. The SFR_G, SFR_R, NBI_G, and NBI_R indices were positively correlated with the N indicators whereas the BRR_FRF, ANTH, and FLAV were inversely associated with them. The $\mathrm{R}^{2}$ of the regression models based on these indices varied from 0.03 to 0.78 . The best performing index varied at different stages, but NBI_G and NBI_R showed steady high correlations with all five $\mathrm{N}$ status indicators. The second-best performing indices were BRR_FRF and FLAV. The SFR_G and SFR_R indices displayed high or moderate correlations with the $\mathrm{N}$ indicators during the PI or HE stage, respectively. 
Table 4. The coefficients of determination $\left(R^{2}\right)$ for the linear relationships between standard and normalized Multiplex indices and $\mathrm{N}$ status indicators (leaf $\mathrm{N}$ concentration (LNC), plant N concentration (PNC), N nutrition index (NNI), aboveground biomass (AGB) and plant $\mathrm{N}$ uptake (PNU)) for two varieties at the panicle initiation (PI), stem elongation (SE), and heading (HE) growth stages.

\begin{tabular}{|c|c|c|c|c|c|c|c|c|c|c|c|c|c|c|c|}
\hline \multirow{2}{*}{ Multiplex Indices } & \multicolumn{3}{|c|}{ LNC $\left(\mathrm{g} \mathrm{kg}^{-1}\right)$} & \multicolumn{3}{|c|}{ PNC $\left(\mathrm{g} \mathrm{kg}^{-1}\right)$} & \multicolumn{3}{|c|}{ NNI } & \multicolumn{3}{|c|}{ AGB (t ha $\left.{ }^{-1}\right)$} & \multicolumn{3}{|c|}{ PNU (kg ha-1) } \\
\hline & PI & SE & HE & PI & SE & HE & PI & SE & HE & PI & SE & HE & PI & SE & HE \\
\hline \multicolumn{16}{|c|}{ Standard indices } \\
\hline SFR_G & $0.63^{* *}$ & $0.30 * *$ & $0.49 * *$ & $0.64^{* *}$ & $0.34^{* *}$ & $0.46^{* *}$ & $0.72 * *$ & $0.31^{* *}$ & $0.59 * *$ & 0.60 ** & $0.14^{*}$ & $0.41^{* *}$ & $0.66^{* *}$ & $0.21^{* *}$ & $0.58^{* *}$ \\
\hline SFR_R & $0.59^{* *}$ & $0.28 * *$ & $0.42 * *$ & $0.58^{* *}$ & $0.34^{* *}$ & $0.38^{* * *}$ & $0.66^{* *}$ & $0.29 * *$ & $0.54^{* *}$ & $0.56^{* *}$ & $0.13 *$ & $0.45^{* *}$ & $0.61^{* *}$ & $0.19^{* *}$ & $0.57^{* *}$ \\
\hline BRR_FRF & $0.53^{* *}$ & $0.52 * *$ & $0.67^{* *}$ & $0.47^{* *}$ & $0.48^{* *}$ & $0.66^{* *}$ & $0.57^{* *}$ & $0.48^{* *}$ & $0.72 * *$ & 0.50 ** & $0.26^{* *}$ & $0.33^{* *}$ & $0.54^{* *}$ & $0.39^{* *}$ & $0.59^{* *}$ \\
\hline FLAV & $0.40 * *$ & $0.64^{* *}$ & $0.55^{* *}$ & $0.39^{* *}$ & $0.64^{* *}$ & $0.55^{* *}$ & $0.58^{* *}$ & $0.73^{* *}$ & $0.67^{* *}$ & $0.55^{* *}$ & $0.50 * *$ & $0.38^{* *}$ & $0.59^{* *}$ & $0.68^{* *}$ & $0.59 * *$ \\
\hline ANTH & $0.38^{* *}$ & $0.12 *$ & $0.27^{* *}$ & $0.41^{* *}$ & $0.14^{*}$ & $0.33^{* *}$ & $0.60 * *$ & $0.10 *$ & $0.47^{* *}$ & 0.60 ** & $0.03 \mathrm{NS}$ & $0.36^{* *}$ & $0.61^{* *}$ & $0.06 \mathrm{NS}$ & $0.48^{* *}$ \\
\hline NBI_G & $0.54^{* *}$ & $0.68^{* *}$ & $0.62 * *$ & $0.52 * *$ & $0.71^{* *}$ & $0.61 * *$ & $0.69^{* *}$ & $0.78^{* *}$ & $0.76^{* *}$ & $0.63^{* *}$ & $0.50 * *$ & $0.47^{* *}$ & $0.68^{* *}$ & $0.71^{* *}$ & $0.71^{* *}$ \\
\hline NBI_R & 0.52 ** & $0.67^{* *}$ & $0.58^{* *}$ & $0.52 * *$ & $0.71^{* *}$ & $0.56^{* *}$ & $0.70^{* *}$ & $0.77^{* *}$ & $0.74^{* *}$ & $0.64^{* *}$ & $0.47^{* *}$ & $0.51^{* *}$ & $0.69^{* *}$ & $0.68^{* *}$ & $0.72^{* *}$ \\
\hline \multicolumn{16}{|c|}{ Normalized indices } \\
\hline SFR_G ${ }_{N S I}$ & $0.58^{* *}$ & $0.39 * *$ & $0.67^{* *}$ & $0.65^{* *}$ & $0.42 * *$ & $0.70^{* *}$ & $0.55^{* *}$ & $0.54^{* *}$ & $0.69^{* *}$ & $0.35^{* *}$ & $0.45^{* *}$ & $0.24^{* *}$ & $0.43^{* *}$ & $0.50^{* *}$ & 0.52 ** \\
\hline SFR_R ${ }_{N S I}$ & $0.57^{* *}$ & $0.42 * *$ & $0.62 * *$ & $0.61^{* *}$ & $0.46^{* *}$ & $0.67^{* *}$ & $0.52 * *$ & $0.57 * *$ & $0.68^{* *}$ & $0.33^{* *}$ & $0.45 * *$ & $0.25^{* *}$ & $0.40^{* *}$ & $0.52 * *$ & $0.52 * *$ \\
\hline BRR_FRF $F_{\text {NSI }}$ & $0.49^{* *}$ & $0.34^{* *}$ & $0.63^{* *}$ & $0.48^{* *}$ & $0.41^{* *}$ & $0.74^{* *}$ & $0.41^{* *}$ & $0.56^{* *}$ & $0.76^{* *}$ & $0.26^{* *}$ & $0.50 * *$ & $0.28^{* *}$ & $0.33^{* *}$ & $0.56^{* *}$ & $0.58^{* *}$ \\
\hline FLAV $_{\text {NSI }}$ & $0.42 * *$ & $0.51^{* *}$ & $0.70^{* *}$ & $0.44^{* *}$ & $0.60^{* *}$ & $0.76^{* *}$ & $0.41^{* *}$ & $0.74^{* *}$ & $0.82 * *$ & $0.26^{* *}$ & $0.55^{* *}$ & $0.34^{* *}$ & $0.33^{* *}$ & $0.70^{* *}$ & $0.64^{* *}$ \\
\hline $\mathrm{ANTH}_{\mathrm{NSI}}$ & $0.51^{* *}$ & $0.40 * *$ & $0.57^{* *}$ & $0.64^{* *}$ & $0.40^{* *}$ & $0.65^{* *}$ & $0.54^{* *}$ & $0.57^{* *}$ & $0.56^{* *}$ & $0.34^{* *}$ & $0.52 * *$ & 0.11 * & $0.42^{* *}$ & $0.58^{* *}$ & $0.35^{* *}$ \\
\hline NBI_G ${ }_{N S I}$ & $0.59^{* *}$ & $0.53^{* *}$ & $0.69^{* *}$ & $0.61^{* *}$ & $0.63^{* *}$ & $0.75^{* *}$ & $0.55^{* *}$ & $0.76^{* *}$ & $0.78^{* *}$ & $0.35^{* *}$ & $0.55^{* *}$ & $0.31^{* *}$ & $0.43^{* *}$ & $0.71^{* *}$ & 0.61 ** \\
\hline NBI_R $R_{\text {NSI }}$ & $0.60 * *$ & $0.55^{* *}$ & $0.69^{* *}$ & $0.65^{* *}$ & $0.64^{* *}$ & $0.75^{* *}$ & $0.58^{* *}$ & $0.77^{* *}$ & $0.79^{* *}$ & $0.36^{* *}$ & $0.56^{* *}$ & $0.31^{* *}$ & $0.46^{* *}$ & $0.72^{* *}$ & $0.61^{* *}$ \\
\hline
\end{tabular}


Compared to the counterpart of the standard indices, the normalized sufficiency indices SFR_G $\mathrm{NSI}_{\text {, }}$ SFR_R NSI $_{\text {, and }} \mathrm{ANTH}_{\mathrm{NSI}}$ exhibited better linear relationships with LNC, PNC, and NNI in most of the cases, especially at the SE and HE stages. The NBI_G NSI $_{\text {and NBI_R }}$ NSI displayed enhanced relationships with the LNC and PNC at the PI and HE stages, and with the NNI at the HE stage. The BRR_FRF $F_{\text {NSI }}$, FLAV $_{\text {NSI }}$ showed improved associations with PNC at the PI and HE stages, and with NNI at the SE and HE stages. All the standard indices showed moderate-high relationships with the AGB and PNU during the PI and HE stages, while at the HE stage, greatly improved $\mathrm{R}^{2}$ values were obtained using the normalized indices.

\subsection{Validation of the Estimation Models for N Status Indicators}

In order to diagnose rice $\mathrm{N}$ status, linear regression models between the Multiplex indices and $\mathrm{N}$ indicators were established. The regression models varied across growth stages. Table 5 lists the best performing models at the PI, SE, and HE stages. The best performing indices differed across the stages. However, the relationships of NBI_G and NBI_R with N indicators were relatively more stable. After

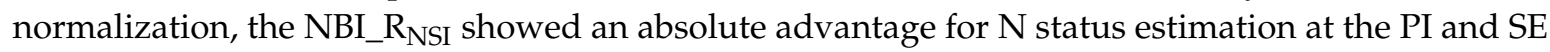

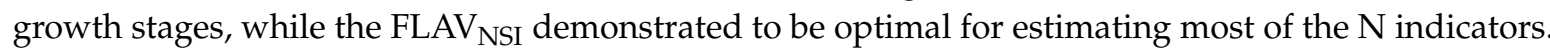

Table 5. Equations and coefficients of determination of linear regression models $(n=40)$ at different growth stages based on the best performing Multiplex index and crop N indicators (LNC, PNC, NNI, PNU, and AGB).

\begin{tabular}{|c|c|c|c|c|c|c|}
\hline Growth Stage & Standard Indices & Model & $\mathbf{R}^{2}$ & Normalized Indices & Model & $\mathbf{R}^{2}$ \\
\hline PI & SFR_G & $\mathrm{LNC}=4.468 \mathrm{x}+5.932$ & 0.63 & NBI_R $R_{N S I}$ & $\mathrm{LNC}=23.918 \mathrm{x}+10.413$ & 0.60 \\
\hline PI & SFR_G & $\mathrm{PNC}=2.912 \mathrm{x}+4.961$ & 0.64 & NBI_R ${ }_{N S I}$ & $\mathrm{PNC}=15.323 \mathrm{x}+8.247$ & 0.65 \\
\hline PI & SFR_G & $\mathrm{NNI}=0.2442 \mathrm{x}-0.5188$ & 0.72 & NBI_R & $\mathrm{NNI}=1.1412 \mathrm{x}-0.1116$ & 0.58 \\
\hline PI & NBI_G & $\mathrm{AGB}=1.5268 \mathrm{x}-1.1565$ & 0.64 & NBI_R $R_{N S I}$ & $\mathrm{AGB}=2.905 \mathrm{x}-1.1184$ & 0.36 \\
\hline SE & NBI_G & $\mathrm{LNC}=8.707 x+14.352$ & 0.68 & NBI_R $R_{N S I}$ & $\mathrm{LNC}=17.96 \mathrm{x}+16.279$ & 0.55 \\
\hline SE & NBI_G & $\mathrm{PNU}=51.494 \mathrm{x}-40.873$ & 0.71 & NBI_R ${ }_{N S I}$ & $\mathrm{PNU}=120.8 \mathrm{x}-42.157$ & 0.72 \\
\hline SE & NBI_G & $\mathrm{AGB}=1.7391 \mathrm{x}-0.4502$ & 0.50 & NBI_R $R_{N S I}$ & $\mathrm{AGB}=4.1975 \mathrm{x}-0.5961$ & 0.56 \\
\hline $\mathrm{HE}$ & BRR_FRF & $\mathrm{LNC}=-210.31 \mathrm{x}+47.452$ & 0.67 & NBI_G ${ }_{N S I}$ & $\mathrm{LNC}=21.646 \mathrm{x}+15.473$ & 0.69 \\
\hline $\mathrm{HE}$ & BRR_FRF & $P N C=-131.79 x+24.313$ & 0.66 & FLAV $_{\text {NSI }}$ & $\mathrm{PNC}=-31.59 x+49.591$ & 0.76 \\
\hline $\mathrm{HE}$ & NBI_G & $\mathrm{NNI}=0.5942 \mathrm{x}-0.054$ & 0.76 & FLAV $_{\text {NSI }}$ & $\mathrm{NNI}=-3.0631 \mathrm{x}+4.3956$ & 0.82 \\
\hline $\mathrm{HE}$ & NBI_R & $\mathrm{PNU}=213.07 x-67.623$ & 0.72 & FLAV $_{\mathrm{NSI}}$ & $\mathrm{PNU}=-462.81 \mathrm{x}+612.19$ & 0.64 \\
\hline
\end{tabular}

Figure 3 shows the RE values of the validation models for six Multiplex indices (SFR_G, SFR_R, BRR_FRF, FLAV, NBI_G, and NBI_R) and the N status indicators. The RE values for AGB and PNU estimations based on these indices decreased steadily with advancing growth stages, while a slightly increasing trend was observed for the LNC and PNC estimation models from the SE to HE stage. The RE values for LNC (4.50\%-10.24\%) and PNC (5.87\%-10.87\%) models were much smaller than those for AGB (15.49\%-30.18\%) and PNU (19.31\%-31.25\%), while the REs of NNI remained similar during the three growth stages. At the earlier to middle growth stages, NBI_R and NBI_G presented a lower $\mathrm{RE}$ than the other four indices for all the five $\mathrm{N}$ indicators. At the HE stage, however, the prediction accuracies of the six indices were similar. 

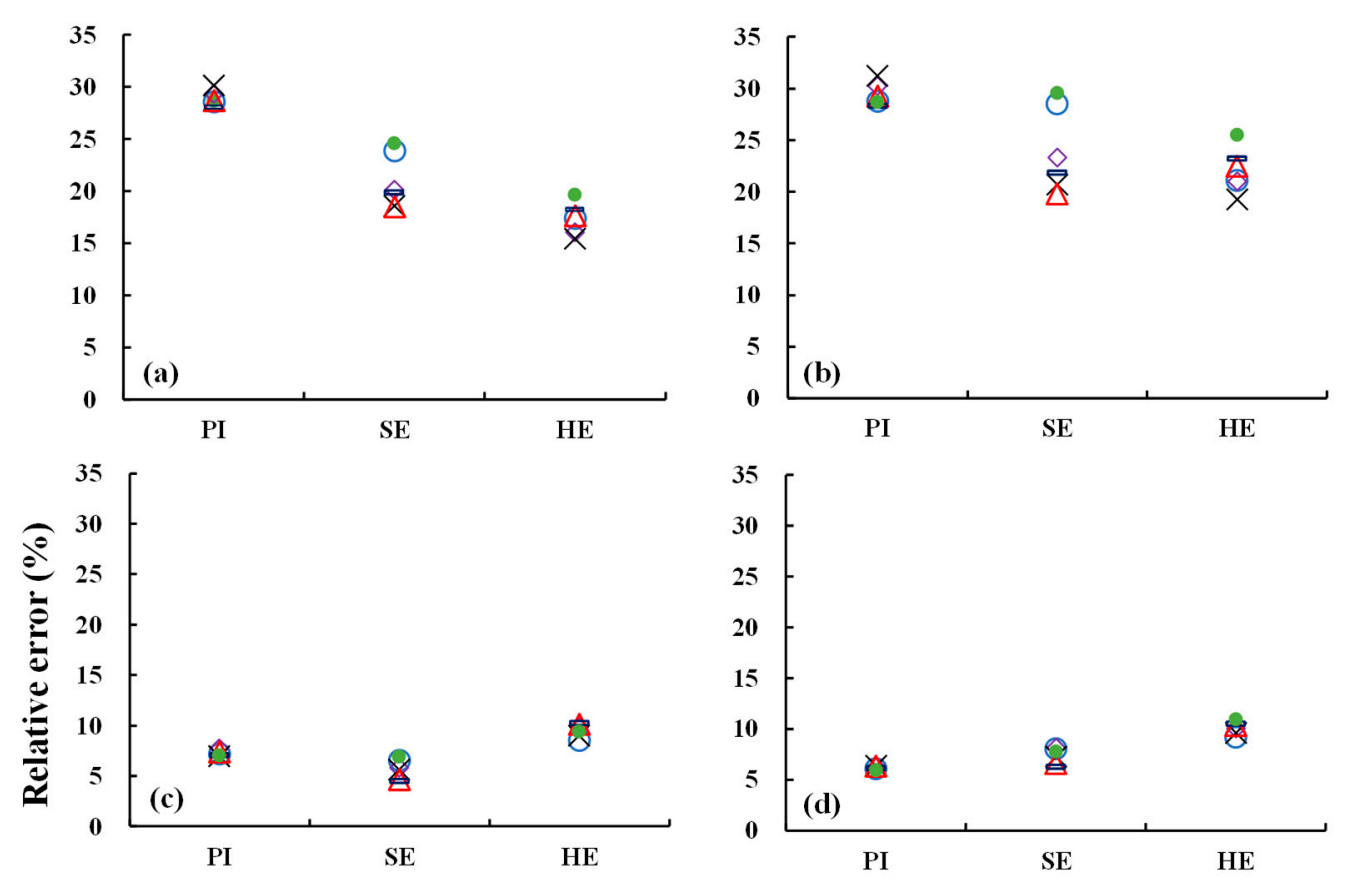

OSFR_G

-SFR R

$\diamond$ BRR FRF

XFLAV

$\triangle$ NBI_G

$-N B I R$

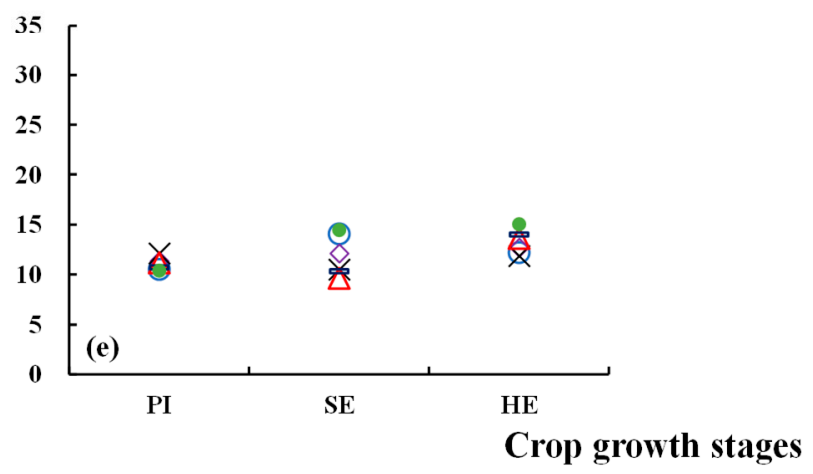

Figure 3. The relative error (RE) values of the validation analysis based on the regression models of the six Multiplex indices and the $\mathrm{N}$ status indicators for (a) above-ground biomass (AGB), (b) plant $\mathrm{N}$ uptake (PNU), (c) leaf $\mathrm{N}$ concentration (LNC), (d) plant $\mathrm{N}$ concentration (PNC), and (e) nitrogen nutrition index (NNI) at the panicle initiation (PI), stem elongation (SE), and heading (HE) stages.

\subsection{Rice N Status Diagnosis}

The best performing indices including SFR_G, BRR_FRF, NBI_G, NBI_R, NBI_G NSI $_{\text {, NBI_R }}$ NSI and FLAV $_{\text {NSI }}$ were validated using independent data sets (Table 5). Moderate-high model performance with $R^{2}$ ranging from 0.34 to 0.82 was observed, especially for the LNC, PNC, and NNI estimations. The areal agreement and Kappa statistics were compared at the critical $\mathrm{N}$ fertilizer application stages (SE and HE) to evaluate the N diagnostic accuracies of the indices. Results confirmed that the NNI models based on NBI_R and NBI_G performed consistently well at the SE and HE growth stages, and their corresponding NSI indices further improved the results (Table 6). At the SE stage, the NBI_R $\mathrm{RSI}_{\mathrm{N}}$ achieved the highest diagnostic accuracy (areal agreement $=90 \%$; Kappa $=0.84$ ), while the best accuracy was achieved by FLAV at the HE stage (areal agreement $=90 \%$; Kappa $=0.76$ ). In addition,

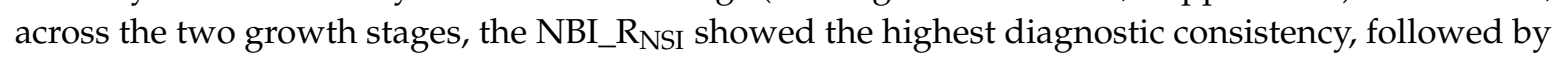
the BRR_FRF NSI. $_{\text {. }}$ 
Table 6. Agreement and Kappa statistics for different indices (SFR_G, SFR_R, BRR_FRF, FLAV, ANTH, NBI_G, and NBI_R) and corresponding normalized indices (SFR_G ${ }_{N S I}$, SFR_R NSI $_{\text {, BRR_FRF }}$ NSI, $\mathrm{FLAV}_{\mathrm{NSI}}, \mathrm{ANTH}_{\mathrm{NSI}}, \mathrm{NBI} \mathrm{G}_{\mathrm{NSI}}$, and NBI_R $\mathrm{NSI}_{\text {) }}$ regarding diagnostic results (Nitrogen Nutrition Index) at different growth stages.

\begin{tabular}{|c|c|c|c|c|c|c|c|c|c|}
\hline \multirow{2}{*}{ Comparison } & \multicolumn{2}{|c|}{ Agreement (\%) } & \multicolumn{2}{|c|}{ Kappa statistics } & \multirow{2}{*}{ Comparison } & \multicolumn{2}{|c|}{ Agreement (\%) } & \multicolumn{2}{|c|}{ Kappa statistics } \\
\hline & SE & HE & SE & HE & & SE & HE & $\mathrm{SE}$ & HE \\
\hline SFR_G and NNI & 75 & 65 & $0.554^{* * *}$ & 0.310 * & SFR_G & 70 & 85 & $0.494^{* *}$ & $0.661^{* * *}$ \\
\hline SFR_R and NNI & 70 & 70 & $0.510^{* * *}$ & $0.322 *$ & SFR_R RSI and NNI & 75 & 85 & $0.583^{* * *}$ & $0.661^{* * *}$ \\
\hline BRR_FRF and NNI & 60 & 70 & $0.363 *$ & $0.409 * *$ & BRR_FRF $F_{\text {NSI }}$ and NNI & 80 & 80 & $0.655^{* * *}$ & $0.538^{* * *}$ \\
\hline FLAV and NNI & 75 & 90 & $0.605^{* * *}$ & $0.763^{* * *}$ & $\mathrm{FLAV}_{\mathrm{NSI}}$ and NNI & 75 & 80 & $0.558^{* * *}$ & $0.570^{* * *}$ \\
\hline ANTH and NNI & 55 & 75 & $0.283 \mathrm{NS}$ & $0.355^{*}$ & $\mathrm{ANTH}_{\mathrm{NSI}}$ and NNI & 80 & 65 & $0.669^{* * *}$ & $0.227 \mathrm{NS}$ \\
\hline NBI_G and NNI & 75 & 80 & $0.595^{* * *}$ & $0.590^{* * *}$ & NBI_G ${ }_{N S I}$ and NNI & 75 & 85 & $0.673^{* * *}$ & $0.698^{* * *}$ \\
\hline NBI_R and NNI & 75 & 80 & $0.595^{* * *}$ & $0.590^{* * *}$ & NBI_R NSI $_{\text {and NNI }}$ & 90 & 85 & $0.840^{* * *}$ & $0.698^{* * *}$ \\
\hline
\end{tabular}

*** Significant at the 0.001 level; ${ }^{* *}$ Significant at the 0.01 level; ${ }^{*}$ Significant at the 0.05 level; NS Not significant.

\section{Discussion}

\subsection{Multiplex Measurement Modes and Estimation of Crop N Indicators by Fluorescence Indices}

The $\mathrm{N}$ treatment effects were more significant for the readings obtained in the OG mode than those collected in the AC mode (Table 3, Figure 2), which is different from the finding by Diago et al. [39] who reported a $20 \%$ loss of information occurred when using the Multiplex on-the-go (compared to the AC mode) for $\mathrm{N}$ assessment of grapevine. This is because the OG measurements in this study were taken manually by placing the Multiplex sensor right on the top of the rice rather than a small distance above the rice canopy while passing through the rice paddy. In contrast, in the study by Diago et al. [39], the Multiplex sensor was mounted onto an all-terrain vehicle and placed $1.5 \mathrm{~m}$ above the ground so that the leaves on the mid-part of the canopy were automatically measured at a $20 \mathrm{~cm}$ distance, the same measuring distance as their AC mode. In addition, this study revealed that measurements made using the LS mode were the least sensitive to N supply, contrasting to the result by Zhang et al. [41] who found Multiplex measurements made from corn leaves were more capable of distinguishing plant $\mathrm{N}$ status than those made from above the plants. While the leaf scale measurements made in this study were collected in the laboratory by taking ten leaves in the second position from the top, the leaf-borne measurements by Zhang et al. [41] were made on 20 representative plants in the center two rows of each plot in the field, which is more similar to the OG rather than the LS method in this study. Another possible reason for their better results with the LS method is that the OG measurements do not give much time to choose leaves and result in more random leaf choosing than the LS method, which may have an unwanted tendency to choose "good" leaves. This is particularly true for maize, because systematic use of a representative leaf is easier, as it is well known which is the most representative leaf for each growth stage, given its determined growth. For rice, the individual leaves are quite small and the signal obtained during the measurements taken on a leaf is relatively weak and can be easily affected by other factors. One advantage the "measuring in motion" or OG mode has is efficiency, especially when the sensor is mounted on a vehicle or other automatic devices, which might make practical applications of such non-destructive technology over large areas possible. Bringing the sensor close to or even touching the leaves of the crop in OG mode may help reduce information loss. However, further well-designed studies are needed to confirm this finding.

Strong relationships between the Multiplex indices (SFR_G, SFR_R, BRR_FRF, FLAV, NBI_G, and NBI_R) measured in the OG mode and the five $\mathrm{N}$ indicators were achieved with low RE and high $\mathrm{R}^{2}$ values (Table 4, Figure 3). This finding conforms to previous research results in this field $[26,42,55,56]$. Many studies confirmed SFR was a good fluorescence index for chlorophyll content monitoring $[24,38,57]$. However, in this study, it was found that the $R^{2}$ of the SFR_G, SFR_R for LNC, $\mathrm{PNC}$, and NNI estimation decreased steadily from the early-stage to later stages, while an opposite trend was observed for FLAV. Padilla et al. [55] found that the relationships between the NNI and SFR_G changed with the phenological stages of cucumber (Cucumis sativus L.). Firstly, the consistency of the relationship between chlorophyll content and $\mathrm{N}$ concentration varied with crop development, 
leading to different performances of SFR for $\mathrm{N}$ concentration estimation. For example, the linear correlation between LNC and chlorophyll meter readings of rice was weaker at the SE stage than at other growth stages [58]. Secondly, the weaker differentiation ability of SFR under the unlimited N conditions may also be a reason [55]. The performance of FLAV increased from the PI to HE stages, which was confirmed by Padilla et al. [59], who found the relationship of FLAV and NNI increased at the middle to late growth stages. The better performance of FLAV at the later stage may be attributed to the accumulation of the flavonols content in leaves under light radiation [44,60]. The NBI_G and NBI_R indices were shown as the best indices for estimating the $\mathrm{N}$ indicators (Table 5). Many studies have proven that the NBI indices appeared to be the most efficient in estimating the N status $[47,56,59,61]$. This is because the NBI is a ratio of SFR and FLAV, which makes it more robust than using FLAV or SFR alone to reduce the effects of leaf age or other factors [34,36,47]. The NBI_G and NBI_R had similar performance in this study, as demonstrated by Longchamps and Khosla [27]. Moreover, Longchamps and Khosl [27] found that SFR was less sensitive to N application than NBI, which conforms to our results, as shown in Figure 2. In most cases, the SFR_G and SFR_R indices could not distinguish between the 100 and $130 \mathrm{~kg} \mathrm{~N} \mathrm{ha}^{-1}$ treatments, but NBI could. The BRR_FRF index was significantly correlated with the $\mathrm{N}$ nutritional status and was especially sensitive to $\mathrm{N}$ deficiency in this research. When there is $\mathrm{N}$ stress, the fluorescence ratio of blue-green/far-red will increase after exposure to elevated UV radiation to avoid or alleviate the damage of the photosynthetic apparatus [62]. Generally, the UV-protection response takes place before the chlorophyll damage can be seen, so the BRR_FRF can also be considered as a potential index that can realize early $\mathrm{N}$ deficiency detection [63]. The BRR_FRF was also very sensitive to environmental stresses, such as disease and drought $[38,63,64]$. The ANTH index provided by Multiplex is commonly used to reflect anthocyanin content, which corresponds to the maturation degree of fruit $[49,65]$. In this research, the low values of ANTH were due to the low anthocyanin content in the rapid vegetative growth phase for rice [66]. Nevertheless, ANTH was also found to be closely related to the leaf chlorophyll concentration in some studies $[38,41]$. This study revealed that ANTH was significantly related to N status indicators in PI and HE growth stages with moderate $\mathrm{R}^{2}$ values (Table 4 ).

\subsection{Normalized Nitrogen Sufficiency Fluorescence Indices}

Our research involved two years and two varieties of experiments. In these experiments, N fertilization rate is the main variable, and the variation is so high that it will probably override any other source of variation. In a commercial field, many factors can influence $\mathrm{N}$ availability, $\mathrm{N}$ and Chlorophyll relationship, or Chlorophyll (+FLAV and ANTH) relations to fluorescence indices, including biotic or abiotic stresses at the moment of measurement or in the history of the crop or even the field. The normalized $\mathrm{N}$ sufficiency index approach has been suggested to reduce the influence of the varieties, developmental stages, and other variables on SPAD values or spectral data $[3,11,67]$. From the results of this study, in most cases, the normalized NSIs were better associated with the LNC, PNC, and NNI (Table 4). The $\mathrm{R}^{2}$ of the $\mathrm{ANTH}_{\text {NSI }}$ was improved the most, followed by the NBI_G $\mathrm{G}_{\mathrm{NSI}}$ and NBI_R $R_{\text {NSI. }}$. However, the improvement in $R^{2}$ for BRR_FRF $F_{\text {NSI }}$ was minimal. The variance analysis of this study showed consistent results, which demonstrated that NSI indices could reduce the influence of inter-annual and growth stage differences. Since NNI itself is a diagnostic criterion, it represents an optimal N status when NNI is equal to one [68]. Most of the NSI indices greatly improved the NNI diagnostic accuracy at the critical topdressing (SE and HE) stages (Table 6). Similarly, Lu et al. [43] observed that the NNI inversion through the normalized vegetation indices further improved the N nutrition diagnostic results of rice.

Hussain et al. [69] proposed a critical NSI value of 0.90 for rice. However, in this study, when the NSI indices were 0.90 , different optimal NNI values, ranging from 0.85 to 2.14 , were derived by different indices at different developmental stages. Only the corresponding optimal NNI values for the NBI_G NSI $_{\text {and NBI_R }}$ NSI indices were close to one (ranging from 0.91 to 1.19). Therefore, to avoid the risk of misdiagnosis, the NSI threshold was not used as a diagnostic criterion directly. A possible 
reason for this is that the $\mathrm{N}$ fertilizer application rate in this study was only 1.3-1.6 times higher than the optimal amount instead of 1.8-2.0 times higher than recommended for the well-fertilized $\mathrm{N}$ plot as Hussain et al. [69] suggested. Furthermore, all of the Multiplex indices were divided by the readings of the $\mathrm{N}$ rate with the largest shoot dry matter at each sampling date to obtain a sufficiency index. However, Varvel et al. [70] suggested that the maximum readings within each cropping system, variety, and year should be considered as the normalized criterion. Obviously, with different normalization criteria, different sufficiency indices will be obtained, which will affect the corresponding analysis results. Another limitation of the NSI approach is that well-fertilized reference plots need to be established in each farmer's field for practical application purposes, and some farmers may not be willing to do this. More in-depth and systematic research is expected in the future.

\subsection{The Application Potential of the Multiplex Sensor}

The Multiplex indices presented good $\mathrm{R}^{2}$ values for LNC and PNC estimations at the earlier growth stages (Table 4). In particular, the validation data showed that the RE values for LNC and PNC estimations were as low as $6 \%-7 \%$ (Figure 3c,d). This is consistent with the results of Cerovic et al. [71] and Agati et al. [56], who have shown a high correlation between the fluorescence index and LNC. NBI and LNC had a fairly linear relationship. Therefore, the NBI indices can be used to more accurately estimate a wider range of LNC. Agati et al. [56] also found the results based on reflectance imaging (camera picture) are less sensitive to $\mathrm{N}$ application than fluorescence-based indices. Research by Stroppiana et al. [72] and Yu et al. [19] on rice showed unsatisfactory results for the estimation of LNC and PNC based on reflectance spectroscopy. This is possibly due to the fact that the effect of $\mathrm{N}$ on the leaf area index and biomass is much greater than its effect on chlorophyll content. Second, near-infrared radiation is hardly absorbed in the canopy and is highly transmissive, so its correlation with leaf area index or biomass is extremely high; while visible light, especially the blue and red radiation, is easily absorbed by chlorophyll and its transmittance is low, so it is highly correlated with chlorophyll content $[15,72]$. On the other hand, changes in plant metabolism indicators are fast or slow due to changes in response to the environment. However, the sensitivity of reflectance-based parameters does not always provide satisfactory monitoring results [73]. Demotes-Mainard et al. [74] observed that changes in $\mathrm{N}$ concentration took precedence over changes in biomass. Thus, fluorescence-based techniques that are highly sensitive to plant $\mathrm{N}$ status information may address the limitation of reflectance-based methods [27,73]. Similarly, the Multiplex indices, especially the NBI_G and NBI_R, presented accurate estimation for NNI, with $\mathrm{R}^{2}$ reaching a maximum of $0.72-0.78$, and the validation results also showed a low inversion error for NNI (RMSE $\leq 0.16, \mathrm{RE} \leq 15 \%$ ) (Table 4). Many studies have confirmed that NBI has a strong estimation potential for NNI [47,55,59]. This is because NBI is the ratio of SFR to FLAV. The SFR index was considered to be an important parameter for estimating chlorophyll concentration, which was often used as an index of surface-based N [75], while the FLAV parameter directly reflects flavonol content, which is controlled by light as well as leaf mass per area, and has a strong correlation with leaf mass [76]. Therefore, NBI as the SFR/FLAV ratio is the best $\mathrm{N}$ nutrition diagnostic index.

The fluorescence-based indices are more sensitive to chlorophyll or $\mathrm{N}$ content than the reflectance-based indices and can detect the difference in $\mathrm{N}$ nutrition status earlier. However, the difference of the stage-based models between the indices and the $\mathrm{N}$ nutrition indicators based on the canopy reflectance instrument is smaller than that based on fluorescence [59]. The surface area of the crop involved in each test when using the canopy reflectance spectroscopy sensors is larger than the fluorescence sensors [59]. Therefore, canopy reflectance measurements are more representative, while fluorescence instruments require increasing the number of tests to obtain sufficiently representative data. Although the performance of the fluorescence sensor was quite good for estimating LNC, PNC, and NNI, $22 \%-60 \%$ of their variability was still not explained. In addition, the fluorescence sensor did not perform very well for estimating plant biomass in the middle to late stages (Table 4). It has 
been suggested to combine the fluorescence and reflectance data to improve the estimation of plant $\mathrm{N}$ status $[3,73]$. This may be one of the important research directions in the future.

\section{Conclusions}

This research compared the LS, OG, and AC measurement modes of the fluorescence instrument Multiplex ${ }^{\circledR} 3$ and determined that the OG mode was best suited for this rice $\mathrm{N}$ status study. Using the OG mode, stable test results and crop growth information were derived. The results revealed that the fluorescence indices of NBI, SFR, BRR_FRF, and FLAV were significantly correlated to all five N status indicators from the PI through HE growth stages. Among them, NBI_G and NBI_R were the best performing indices and highly correlated to LNC $\left(R^{2}=0.52-0.68\right)$, PNC $\left(R^{2}=0.52-0.71\right)$, NNI $\left(R^{2}=0.69-0.78\right)$, AGB $\left(R^{2}=0.47-0.64\right)$, and PNU $\left(R^{2}=0.68-0.72\right)$ at the three growth stages. The normalized sufficiency indices of the Multiplex parameters could greatly improve the LNC, PNC, and NNI estimation ability, especially at the HE stage. The $\mathrm{N}$ diagnostic results indicated that the NBI_R $R_{\text {NSI }}$ and FLAV achieved the highest diagnostic accuracy rate $(90 \%)$ at the SE and HE stage, respectively, while NBI_R $R_{\text {NSI }}$ showed the highest analytical consistency across growth stages. The results suggest that the Multiplex sensor can be used to reliably estimate $\mathrm{N}$ nutritional status for rice in cold regions, especially for the estimation of LNC, PNC, and NNI. The normalized sufficiency indices based on Multiplex indices may further improve the accuracy of $\mathrm{N}$ nutrition diagnosis by reducing the differences between years and varieties.

Author Contributions: Y.M. and G.B. conceived and guide the study. S.H. and Q.C. conducted the field experiments. S.H. and H.Y. performed the data analysis. S.H. wrote the original manuscript. Y.M., F.Y. and V.I.S.L.-W. revised the manuscript. G.B. and H.Y. reviewed and edited the manuscript. All authors read and approved the final manuscript.

Funding: This research was financially supported by the National Key Research and Development Program of China (2016YFD0200600, 2016YFD0200602), National Basic Research Program (2015CB150405), and the Norwegian Ministry of Foreign Affairs (SINOGRAIN II, CHN-17/0019).

Acknowledgments: We would like to thank the supports by Wen Yang, Huamin Zhu, and Fengyan Liu at the Jiansanjiang Institute of Agricultural Sciences. We also would like to thank Jianning Shen, Weifeng Yu, and Shanshan Cheng for their fieldwork and contributions in spectral data collection.

Conflicts of Interest: The authors declare no conflict of interest.

\section{References}

1. Guo, J.H.; Liu, X.J.; Zhang, Y.; Shen, J.L.; Han, W.X.; Zhang, W.F.; Christie, P.; Goulding, K.W.; Vitousek, P.M.; Zhang, F.S. Significant acidification in major Chinese croplands. Science 2010, 327, 1008-1010. [CrossRef]

2. Miao, Y.; Stewart, B.A.; Zhang, F. Long-term experiments for sustainable nutrient management in China. A review. Agron. Sustain. Dev. 2011, 31,397-414. [CrossRef]

3. Samborski, S.M.; Tremblay, N.; Fallon, E. Strategies to make use of plant sensors-based diagnostic information for nitrogen recommendations. Agron. J. 2009, 101, 800-816. [CrossRef]

4. Evans, J.R. Nitrogen and photosynthesis in the flag leaf of wheat (Triticum aestivum L.). Plant Physiol. 1983, 72, 297-302. [CrossRef] [PubMed]

5. Blackmer, T.M.; Schepers, J.S. Use of a chlorophyll meter to monitor nitrogen status and schedule fertigation for corn. J. Prod. Agric. 1995, 8, 56-60. [CrossRef]

6. Schlemmer, M.R.; Francis, D.D.; Shanahan, J.F. Remotely measuring chlorophyll content in corn leaves with differing nitrogen levels and relative water content. Agron. J. 2005, 97, 106-112. [CrossRef]

7. Schröder, J.J.; Neeteson, J.J.; Oenema, O.; Struik, P.C. Does the crop or the soil indicate how to save nitrogen in maize production? Reviewing the state of the art. Field Crop Res. 2000, 66, 151-164. [CrossRef]

8. Schepers, J.S.; Blackmer, T.M.; Francis, D.D. Predicting N fertilizer needs for corn in humid regions: Using chlorophyll meters. In Predicting N Fertilizer Needs for Corn in Humid Regions; Bock, B.R., Kelley, K.R., Eds.; National Fertilizer and Environmental Research Center: Muscle Shoals, AL, USA, 1992; pp. 105-114.

9. Schepers, J.S.; Francis, D.D.; Vigil, M.; Below, F.E. Comparison of corn leaf nitrogen concentration and chlorophyll meter readings. Commun. Soil Sci. Plan. 1992, 23, 2173-2187. [CrossRef] 
10. Markwell, J.; Osterman, J.C.; Mitchell, J.L. Calibration of the Minolta SPAD-502 leaf chlorophyll meter. Photosynth. Res. 1995, 46, 467-472. [CrossRef]

11. Lin, F.F.; Qiu, L.F.; Deng, J.S.; Shi, Y.Y.; Chen, L.S.; Wang, K. Investigation of spad meter-based indices for estimating rice nitrogen status. Comput. Electron. Agric. 2010, 71, S60-S65. [CrossRef]

12. Ali, M.M.; Al-Ani, A.; Eamus, D.; Tan, D.K.Y. Leaf nitrogen determination using non-destructive techniques-A review. J. Soil Sci. Plant Nutr. 2017, 40, 928-953.

13. Mulla, D.J.; Miao, Y. Precision Farming. In Land Resources Monitoring, Modeling, and Mapping with Remote Sensing; Thenkabail, P.S., Ed.; CRC Press: Boca Raton, FL, USA, 2016.

14. Gitelson, A.A.; Gritz, Y.; Merzlyak, M.N. Relationships between leaf chlorophyll content and spectral reflectance and algorithms for non-destructive chlorophyll assessment in higher plant leaves. J. Plant Physiol. 2003, 160, 271-282. [CrossRef] [PubMed]

15. Heege, H.J.; Reusch, S.; Thiessen, E. Prospects and results for optical systems for site-specific on-the-go control of nitrogen-top-dressing in Germany. Precis. Agric. 2008, 9, 115-131. [CrossRef]

16. Yao, Y.; Miao, Y.; Huang, S.; Gao, L.; Ma, X.; Zhao, G.; Jiang, R.; Chen, X.; Zhang, F.; Yu, K.; et al. Active canopy sensor-based precision $n$ management strategy for rice. Agron. Sustain. Dev. 2012, 32, 925-933. [CrossRef]

17. Cao, Q.; Miao, Y.; Shen, J.; Yu, W.; Yuan, F.; Cheng, S.; Huang, S.; Wang, H.; Yang, W.; Liu, F. Improving in-season estimation of rice yield potential and responsiveness to topdressing nitrogen application with Crop Circle active crop canopy sensor. Precis. Agric. 2016, 17, 136-154. [CrossRef]

18. Olfs, H.W.; Blankenau, K.; Brentrup, F.; Jasper, J.; Link, A.; Lammel, J. Soil-and plant-based nitrogen-fertilizer recommendations in arable farming. J. Soil Sci. Plant Nutr. 2005, 168, 414-431. [CrossRef]

19. Yu, K.; Li, F.; Gnyp, M.L.; Miao, Y.; Bareth, G.; Chen, X. Remotely detecting canopy nitrogen concentration and uptake of paddy rice in the Northeast China Plain. ISPRS J. Photogramm. Remote Sens. 2013, 78, 102-115. [CrossRef]

20. Huang, S.; Miao, Y.; Zhao, G.; Yuan, F.; Ma, X.; Tan, C.; Yu, W.; Gnyp, M.; Lenz-Wiedemann, V.; Rascher, U. Satellite remote sensing-based in-season diagnosis of rice nitrogen status in Northeast China. Remote Sens. 2015, 7, 10646-10667. [CrossRef]

21. Bredemeier, C.; Schmidhalter, U. Laser-induced chlorophyll fluorescence sensing to determine biomass and nitrogen uptake of winter wheat under controlled environment and field condition. In Proceedings of the 5th European Conference on Precision Agriculture, Uppsala, Sweden, 9-12 June 2005; Wageningen Academic Publishers: Wageningen, The Netherlands, 2005; pp. 273-280.

22. McMurtrey, J.E., III; Chappelle, E.W.; Kim, M.S.; Meisinger, J.J.; Corp, L.A. Distinguishing nitrogen fertilization levels in field corn (Zea mays L.) with actively induced fluorescence and passive reflectance measurements. Remote Sens. Environ. 1994, 47, 36-44. [CrossRef]

23. Langsdorf, G.; Buschmann, C.; Sowinska, M.; Babani, F.; Mokry, M.; Timmermann, F.; Lichtenthaler, H.K. Multicolour fluorescence imaging of sugar beet leaves with different nitrogen status by flash lamp UV-excitation. Photosynthetica 2000, 38, 539-551. [CrossRef]

24. Gitelson, A.A.; Buschmann, C.; Lichtenthaler, H.K. The chlorophyll fluorescence ratio F-735/F-700 as an accurate measure of the chlorophyll content in plants. Remote Sens. Environ. 1999, 69, 296-302. [CrossRef]

25. Cerovic, Z.G.; Goutouly, J.P.; Hilbert, G.; Destrac-Irvine, A.; Martinon, V.; Moise, N. Mapping winegrape quality attributes using portable fluorescence-based sensors. Frutic 2009, 9, 301-310.

26. Yang, J.; Wei, G.; Shi, S.; Lin, D.; Sun, J.; Song, S.; Chen, B.; Zhang, Z. Analyzing the performance of fluorescence parameters in the monitoring of leaf nitrogen content of paddy rice. Sci. Rep. 2016, 6, 28787. [CrossRef] [PubMed]

27. Longchamps, L.; Khosla, R. Early detection of nitrogen variability in maize using fluorescence. Agron. J. 2014, 106, 511-518. [CrossRef]

28. Teal, R.K.; Tubana, B.; Girma, K.; Freeman, K.W.; Arnall, D.B.; Walsh, O.; Raun, W.R. In-season prediction of corn grain yield potential using normalized difference vegetation index. Agron. J. 2006, 98, 1488-1494. [CrossRef]

29. Martin, K.L.; Girmaa, K.; Freemana, K.W.; Teala, R.K.; Tubańaa, B.; Arnalla, D.B.; Chunga, B.; Walsha, O.; Solieb, J.B.; Stoneb, M.L.; et al. Expression of variability in corn as influenced by growth stage using optical sensor measurements. Agron. J. 2007, 99, 384-389. [CrossRef]

30. Jones, C.G.; Hartley, S.E. A protein competition model of phenolic allocation. Oikos 1999, 86, 27-44. [CrossRef] 
31. Burchard, P.; Bilger, W.; Weissenbock, G. Contribution of hydroxycinnamates and flavonoids to epidermal shielding of UV-A and UV-B radiation in developing rye primary leaves as assessed by ultraviolet-induced chlorophyll fluorescence measurements. Plant Cell Environ. 2000, 23, 1373-1380. [CrossRef]

32. Knogge, W.; Weissenböck, G. Tissue-distribution of secondary phenolic biosynthesis in developing primary leaves of Avena sativa L. Planta 1986, 167, 196-205. [CrossRef]

33. Cerovic, Z.G.; Ounis, A.; Cartelat, A.; Latouche, G.; Goulas, Y.; Meyer, S.; Moya, I. The use of chlorophyll fluorescence excitation spectra for the non-destructive in situ assessment of UV-absorbing compounds in leaves. Plant Cell Environ. 2002, 25, 1663-1676. [CrossRef]

34. Tremblay, N.; Wang, Z.; Bélec, C. Evaluation of the Dualex for the assessment of corn nitrogen status. J. Soil Sci. Plant Nutr. 2007, 30, 1355-1369. [CrossRef]

35. Tremblay, N.; Wang, Z.; Belec, C. Performance of Dualex in spring wheat for crop nitrogen status assessment, yield prediction and estimation of soil nitrate content. J. Soil Sci. Plant Nutr. 2009, 33, 57-70. [CrossRef]

36. Lejealle, S.; Evain, S. Multiplex: A new diagnostic tool for management of nitrogen fertilization of turgrass. In Proceedings of the 10th International Conference on Precision Agriculture, Denver, CO, USA, 18-21 July 2010.

37. Cerovic, Z.G.; Moise, N.; Agati, G.; Latouche, G.; Ghozlen, N.B.; Meyer, S. New portable optical sensors for the assessment of winegrape phenolic maturity based on berry fluorescence. J. Food Compos. Anal. 2008, 21, 650-654. [CrossRef]

38. Yu, K.; Leufen, G.; Hunsche, M.; Noga, G.; Chen, X.; Bareth, G. Investigation of leaf diseases and estimation of chlorophyll concentration in seven barley varieties using fluorescence and hyperspectral indices. Remote Sens. 2013, 6, 64-86. [CrossRef]

39. Diago, M.P.; Rey-Carames, C.; Le Moigne, M.; Fadaili, E.M.; Tardaguila, J.; Cerovic, Z.G. Calibration of non-invasive fluorescence-based sensors for the manual and on-the-go assessment of grapevine vegetative status in the field. Aust. J. Grape Wine R. 2016, 22, 438-449. [CrossRef]

40. Song, X.; Yang, G.; Yang, C.; Wang, J.; Cui, B. Spatial variability analysis of within-field winter wheat nitrogen and grain quality using canopy fluorescence sensor measurements. Remote Sens. 2017, 9, 237. [CrossRef]

41. Zhang, Y.P.; Tremblay, N.; Zhu, J.J. A first comparison of Multiplex ${ }^{\circledR}$ for the assessment of corn nitrogen status. J. Food Agric. Environ. 2012, 10, 1008-1016.

42. Li, J.W.; Zhang, J.X.; Zhao, Z.; Lei, X.D.; Xu, X.L.; Lu, X.X.; Weng, D.L.; Gao, Y.; Cao, L.K. Use of fluorescence-based sensors to determine the nitrogen status of paddy rice. J. Agric. Sci. 2013, 151, 862-871. [CrossRef]

43. Lu, J.; Miao, Y.; Wei, S.; Li, J.; Yuan, F. Evaluating different approaches to non-destructive nitrogen status diagnosis of rice using portable RapidSCAN active canopy sensor. Sci. Rep. 2017, 7, 14073. [CrossRef]

44. Pedrós, R.; Goulas, Y.; Jacquemoud, S.; Louis, J.; Moya, I. FluorMODleaf: A new leaf fluorescence emission model based on the PROSPECT model. Remote Sens. Environ. 2010, 114, 155-167. [CrossRef]

45. Ounis, A.; Cerovic, Z.G.; Briantais, J.M.; Moya, I. Dual-excitation FLIDAR for the estimation of epidermal UV absorption in leaves and canopies. Remote Sens. Environ. 2001, 76, 33-48. [CrossRef]

46. Agati, G.; Cerovic, Z.G.; Pinelli, P.; Tattini, M. Light-induced accumulation of ortho-dihydroxylated flavonoids as non-destructively monitored by chlorophyll fluorescence excitation techniques. Environ. Exp. Bot. 2011, 73, 3-9. [CrossRef]

47. Cartelat, A.; Cerovic, Z.G.; Goulas, Y.; Meyer, S.; Lelarge, C.; Prioul, J.L.; Barbottin, A.; Jeuffroy, M.H.; Gate, P.; Agati, G. Optically assessed contents of leaf polyphenolics and chlorophyll as indicators of nitrogen deficiency in wheat (Triticum aestivum L.). Field Crop. Res. 2005, 91, 35-49. [CrossRef]

48. Lichtenthaler, H.K. Vegetation stress: An introduction to the stress concept in plants. J Plant Physiol. 1996, 148, 4-14. [CrossRef]

49. Ghozlen, N.B.; Cerovic, Z.G.; Germain, C.; Toutain, S.; Latouche, G. Non-destructive optical monitoring of grape maturation by proximal sensing. Sensors 2010, 10, 10040-10068. [CrossRef] [PubMed]

50. Huang, S.; Miao, Y.; Yuan, F.; Cao, Q.; Ye, H.; Lenz-Wiedemann, V.; Khosla, R.; Bareth, G. Proximal fluorescence sensing for in-season diagnosis of rice nitrogen status. Adv. Anim. Biosci. 2017, 8, 343-348. [CrossRef]

51. Huang, S.; Miao, Y.; Cao, Q.; Yao, Y.; Zhao, G.; Yu, W.; Shen, J.; Yu, K.; Bareth, G. Critical nitrogen dilution curve for rice nitrogen status diagnosis in Northeast China. Pedosphere 2018, 28, 814-822. [CrossRef]

52. Xia, T.; Miao, Y.; Wu, D.; Shao, H.; Khosla, R.; Mi, G. Active optical sensing of spring maize for in-season diagnosis of nitrogen status based on nitrogen nutrition index. Remote Sens. 2016, 8, 605. [CrossRef] 
53. Bausch, W.C.; Khosla, R. QuickBird satellite versus ground-based multi-spectral data for estimating nitrogen status of irrigated maize. Precis. Agric. 2010, 11, 274-290. [CrossRef]

54. Landis, R.J.; Koch, G.G. The measurement of observer agreement for categorical data. Biometrics 1977, 33, 159-174. [CrossRef]

55. Padilla, F.M.; Peña-Fleitas, M.T.; Gallardo, M.; Thompson, R.B. Proximal optical sensing of cucumber crop N status using chlorophyll fluorescence indices. Eur. J. Agron. 2016, 73, 83-97. [CrossRef]

56. Agati, G.; Foschi, L.; Grossi, N.; Volterrani, M. In field non-invasive sensing of the nitrogen status in hybrid bermudagrass (Cynodon dactylon, $\times$ C. transvaalensis, Burtt Davy) by a fluorescence-based method. Eur. J. Agron. 2015, 63, 89-96. [CrossRef]

57. Buschmann, C. Variability and application of the chlorophyll fluorescence emission ratio red/far-red of leaves. Photosynth. Res. 2007, 92, 261-271. [CrossRef] [PubMed]

58. Yuan, Z.; Ata-Ul-Karim, S.T.; Cao, Q.; Lu, Z.; Cao, W.; Zhu, Y.; Liu, X. Indicators for diagnosing nitrogen status of rice based on chlorophyll meter readings. Field Crop. Res. 2016, 185, 12-20. [CrossRef]

59. Padilla, F.M.; Peña-Fleitas, M.T.; Gallardo, M.; Thompson, R.B. Evaluation of optical sensor measurements of canopy reflectance and of leaf flavonols and chlorophyll contents to assess crop nitrogen status of muskmelon. Eur. J. Agron. 2014, 58, 39-52. [CrossRef]

60. Barthod, S.; Cerovic, Z.; Epron, D. Can dual chlorophyll fluorescence excitation be used to assess the variation in the content of UV-absorbing phenolic compounds in leaves of temperate tree species along a light gradient? J. Exp. Bot. 2007, 58, 1753-1760. [CrossRef] [PubMed]

61. Goulas, Y.; Cerovic, Z.G.; Cartelat, A.; Moya, I. Dualex: A new instrument for field measurements of epidermal ultraviolet absorbance by chlorophyll fluorescence. Appl. Opt. 2004, 43, 4488-4496. [CrossRef]

62. Lichtenthaler, H.K.; Schweiger, J. Cell wall bound ferulic acid, the major substance of the blue-green fluorescence emission of plants. J. Plant Physiol. 1998, 152, 272-282. [CrossRef]

63. Buschmann, C.; Lichtenthaler, H.K. Principles and characteristics of multi-colour fluorescence imaging of plants. J. Plant Physiol. 1998, 152, 297-314. [CrossRef]

64. Bürling, K.; Cerovic, Z.G.; Cornic, G.; Ducruet, J.M.; Noga, G.; Hunsche, M. Fluorescence-based sensing of drought-induced stress in the vegetative phase of four contrasting wheat genotypes. Environ. Exp. Bot. 2013, 89, 51-59. [CrossRef]

65. Agati, G.; Pinelli, P.; Cortés, E.S.; Romani, A.; Cartelat, A.; Cerovic, Z.G. Nondestructive evaluation of anthocyanins in olive (Olea europaea) fruits by in situ chlorophyll fluorescence spectroscopy. J. Agric. Food Chem. 2005, 53, 1354-1363. [CrossRef] [PubMed]

66. Chen, Y.; Chen, J.; Yan, B.; Cui, L.; Pan, J.; Kai, G. Agronomic traits of a new characteristic rice line 'Huxuan 102'. Acta Agric. Shanghai 2015, 2, 60-64.

67. Zubillaga, M.; Urricariet, S. Assessment of nitrogen status in wheat using aerial photography. Commun. Soil Sci. Plan. 2005, 36, 1787-1798. [CrossRef]

68. Lemaire, G.; Jeuffroy, M.H.; Gastal, F. Diagnosis tool for plant and crop N status in vegetative stage: Theory and practices for crop N management. Eur. J. Agron. 2008, 28, 614-624. [CrossRef]

69. Hussain, F.; Bronson, K.F.; Peng, S. Use of chlorophyll meter sufficiency indices for nitrogen management of irrigated rice in Asia. Agron. J. 2000, 92, 875-879.

70. Varvel, G.E.; Wilhelm, W.W.; Shanahan, J.F.; Schepers, J.S. An algorithm for corn nitrogen recommendations using a chlorophyll meter based sufficiency index. Agron. J. 2007, 99, 701-706. [CrossRef]

71. Cerovic, Z.G.; Ghozlen, N.B.; Milhade, C.; Obert, M.; Debuisson, S.; Le Moigne, M. Nondestructive diagnostic test for nitrogen nutrition of grapevine (Vitis vinifera L.) based on Dualex leaf-clip measurements in the field. J. Agr. Food Chem. 2015, 63, 3669-3680. [CrossRef] [PubMed]

72. Stroppiana, D.; Boschetti, M.; Brivio, P.A.; Bocchi, S. Plant nitrogen concentration in paddy rice from field canopy hyperspectral radiometry. Field Crop. Res. 2009, 111, 119-129. [CrossRef]

73. Tremblay, N.; Wang, Z.; Cerovic, Z.G. Sensing crop nitrogen status with fluorescence indicators. a review. Agron. Sustain. Dev. 2012, 32, 451-464. [CrossRef]

74. Demotes-Mainard, S.; Boumaza, R.; Meyer, S.; Cerovic, Z.G. Indicators of nitrogen status for ornamental woody plants based on optical measurements of leaf epidermal polyphenol and chlorophyll contents. Sci. Hortic. 2008, 115, 377-385. [CrossRef] 
75. Agati, G.; Foschi, L.; Grossi, N.; Guglielminetti, L.; Cerovic, Z.G.; Volterrani, M. Fluorescence-based versus reflectance proximal sensing of nitrogen content in Paspalum vaginatum and Zoysia matrella turfgrasses. Eur. J. Agron. 2013, 45, 39-51. [CrossRef]

76. Meyer, S.; Cerovic, Z.G.; Goulas, Y.; Montpied, P.; Demotesmainard, S.; Bidel, L.P.; Moya, I.; Dreyer, E. Relationships between optically assessed polyphenols and chlorophyll contents, and leaf mass per area ratio in woody plants: A signature of the carbon-nitrogen balance within leaves? Plant Cell Environ. 2006, 29, 1338-1348. [CrossRef] [PubMed]

(C) 2019 by the authors. Licensee MDPI, Basel, Switzerland. This article is an open access article distributed under the terms and conditions of the Creative Commons Attribution (CC BY) license (http://creativecommons.org/licenses/by/4.0/). 